\title{
IceChrono1: a probabilistic model to compute a common and optimal chronology for several ice cores
}

\author{
F. Parrenin ${ }^{1,2}$, L. Bazin ${ }^{3}$, E. Capron ${ }^{4}$, A. Landais ${ }^{3}$, B. Lemieux-Dudon ${ }^{5}$, and V. Masson-Delmotte ${ }^{3}$ \\ ${ }^{1}$ CNRS, LGGE, 38041 Grenoble, France \\ ${ }^{2}$ Univ. Grenoble Alpes, LGGE, 38041 Grenoble, France \\ ${ }^{3}$ British Antarctic Survey, Madingley Road, High Cross, Cambridge, CB3 0ET, UK \\ ${ }^{4}$ Institut Pierre-Simon Laplace/Laboratoire des Sciences du Climat et de 1'Environnement, UMR 8212, CEA-CNRS-UVSQ, \\ 91191 Gif-sur-Yvette, France \\ ${ }^{5}$ Laboratoire Jean Kuntzmann, Grenoble, France \\ Correspondence to: F. Parrenin (parrenin@ujf-grenoble.fr)
}

Received: 19 September 2014 - Published in Geosci. Model Dev. Discuss.: 14 October 2014

Revised: 8 April 2015 - Accepted: 27 April 201 - Published: 21 May 2015

\begin{abstract}
Polar ice cores provide exceptional archives of past environmental conditions. The dating of ice cores and the estimation of the age-scale uncertainty are essential to interpret the climate and environmental records that they contain. It is, however, a complex problem which involves different methods. Here, we present IceChrono1, a new probabilistic model integrating various sources of chronological information to produce a common and optimized chronology for several ice cores, as well as its uncertainty. IceChrono1 is based on the inversion of three quantities: the surface accumulation rate, the lock-in depth (LID) of air bubbles and the thinning function. The chronological information integrated into the model are models of the sedimentation process (accumulation of snow, densification of snow into ice and air trapping, ice flow), ice- and air-dated horizons, ice and air depth intervals with known durations, $\Delta$ depth observations (depth shift between synchronous events recorded in the ice and in the air) and finally air and ice stratigraphic links in between ice cores. The optimization is formulated as a least squares problem, implying that all densities of probabilities are assumed to be Gaussian. It is numerically solved using the Levenberg-Marquardt algorithm and a numerical evaluation of the model's Jacobian. IceChrono follows an approach similar to that of the Datice model which was recently used to produce the AICC2012 (Antarctic ice core chronology) for four Antarctic ice cores and one Greenland ice core. IceChrono1 provides improvements and simplifications with respect to Datice from the mathematical, numerical and pro-
\end{abstract}

gramming point of views. The capabilities of IceChrono1 are demonstrated on a case study similar to the AICC2012 dating experiment. We find results similar to those of Datice, within a few centuries, which is a confirmation of both IceChronol and Datice codes. We also test new functionalities with respect to the original version of Datice: observations as ice intervals with known durations, correlated observations, observations as air intervals with known durations and observations as mixed ice-air stratigraphic links. IceChrono1 is freely available under the General Public License v3 open source license.

\section{Introduction}

Polar ice cores provide continuous records of key past features of the climate and the environment, with local, regional and global relevance (e.g., PAGES 2k consortium, 2013; EPICA community members, 2004; NorthGRIP project members, 2004; WAIS Divide Project Members, 2013). Tracers of polar climate (e.g., Jouzel et al., 2007), ice sheet topography (NEEM community Members, 2013), water cycle (e.g., Schoenemann et al., 2014; Stenni et al., 2010; Winkler et al., 2012), aerosol deposition (e.g., Lambert et al., 2012; Wolff et al., 2006) and global atmospheric composition (e.g., Ahn and Brook, 2014; Loulergue et al., 2008; Marcott et al., 2014) measured in ice cores unveil sequences of events on seasonal to glacial-interglacial timescales. 
However, prior to the interpretation of polar ice core records is the complex task of building two robust timedepth relationships, one for the tracers measured in the ice phase (e.g., water isotopes, particulates and chemical impurities) and one for those measured in the air phase (e.g., greenhouse gas concentration, isotopic composition of gases). The firn, where snow is gradually compacted into ice, constitutes the upper $50-120 \mathrm{~m}$ part of ice sheets. The firn is permeable and air is only locked in at its base, at a depth level called the lock-in depth (LID). As a result, the entrapped air is always younger than the surrounding ice at any depth level. Through gravitational fractionation processes, LID is closely related to the isotopic composition of $\delta^{15} \mathrm{~N}$ of $\mathrm{N}_{2}$ in air bubbles data (e.g., Buizert et al., 2015; Goujon et al., 2003; Parrenin et al., 2012a; Schwander et al., 1993). The temporal evolution of the age difference between ice and air at a given depth must therefore be estimated using firn densification modeling and air $\delta^{15} \mathrm{~N}$. This age difference is essential for clarifying the exact timing between changes in atmospheric $\mathrm{CO}_{2}$ concentration and Antarctic surface temperature during deglaciations ( e.g., Caillon et al., 2003; Landais et al., 2013; Monnin et al., 2001; Parrenin et al., 2013; Pedro et al., 2011). However, glacial-interglacial Antarctic firn changes remain poorly understood (e.g., Capron et al., 2013).

Several strategies have been developed to build ice and gas chronologies. We briefly describe these methods, their strengths and caveats hereafter.

- Annual layer counting (e.g., Rasmussen et al., 2006; WAIS Divide Project Members, 2013; Winstrup et al., 2012). Only applicable when accumulation rates are sufficiently high to make this annual layer identification possible, this method provides accurate estimates of event durations and small uncertainties on the absolute age of the upper ice sections. However, the cumulative nature of the errors, associated with the increasing number of counted layers, leads to a decrease of the accuracy of absolute age with depth. For instance, the GICC05 (Greenland Ice Core Chronology 2005) composite timescale for Greenland ice cores (Rasmussen et al., 2006; Seierstad et al., 2014; Svensson et al., 2008) is associated with a maximum counting error of only $45 \mathrm{yr}$ at $\sim 8.2 \mathrm{kyr}$ B1950 (before 1950, current era). This error increases progressively with depth, reaching more than $2500 \mathrm{yr}$ at $\sim 60 \mathrm{kyr}$ B1950. Annual layer counting techniques cannot be applied when the annual layer thickness is too small to be resolved visually, e.g., in ice cores from central East Antarctica.

- Use of absolute age markers in ice cores. Well-dated tephra layers identified in ice cores during the last millennia provide valuable constraints (e.g., Sigl et al., 2014). Beyond that period, absolute age markers are very scarce. The links between ${ }^{10} \mathrm{Be}$ peaks and welldated magnetic events (Raisbeck et al., 2007) have provided an age marker for the Laschamp event (Singer et al., 2009). Promising results have recently been obtained using radiochronologic dating tools (Aciego et al., 2011; Buizert et al., 2014; Dunbar et al., 2008).

- Orbital dating in ice cores. Because there are few absolute constraints in ice cores beyond $60 \mathrm{kyr}$ B1950 (limit for the layer counting in the NGRIP ice core), orbital tuning is the most effective method to provide chronological constraints on an ice core's deepest sections. In the first orbital dating exercises, tie points were determined from the tuning of water isotopic records on insolation curves (e.g., Parrenin et al., 2004), which limits further investigations of polar climate relationships with orbital forcing. More recent chronologies tried to circumvent this assumption and focused on non-climatic orbital markers. Three complementary tracers are currently used: the $\delta^{18} \mathrm{O}$ of atmospheric $\mathrm{O}_{2}\left(\delta^{18} \mathrm{O}_{\text {atm }}\right)$ (e.g., Bender et al., 1994; Dreyfus et al., 2007), $\delta \mathrm{O}_{2} / \mathrm{N}_{2}$ (e.g., Bender, 2002; Kawamura et al., 2007; Suwa and Bender, 2008) and the total air content (e.g., Raynaud et al., 2007). While the link between $\delta^{18} \mathrm{O}_{\mathrm{atm}}$ and precession is explained by variations in the water cycle of the low latitudes, relationships between $\delta \mathrm{O}_{2} / \mathrm{N}_{2}$, air content and local summer insolation are understood to arise from changes in the surface snow energy budget influencing its metamorphism. Without a precise understanding of mechanisms linking these tracers to their respective orbital targets, the associated uncertainties remain large, $6 \mathrm{kyr}$ for $\delta^{18} \mathrm{O}_{\text {atm }}$ and 3-4 kyr for $\delta \mathrm{O}_{2} / \mathrm{N}_{2}$ and air content (Bazin et al., 2013, 2014; Landais et al., 2012).

- Ice core record synchronization. Inter-ice core matching exercises are undertaken to transfer absolute or orbital dating information from one ice core to another one. It generally relies on the global synchroneity of changes in atmospheric composition $\left(\mathrm{CO}_{2}, \mathrm{CH}_{4}\right.$ concentration, and $\delta^{18} \mathrm{O}_{\mathrm{atm}}$ ) (Bender et al., 1994; Blunier and Brook, 2001; Monnin et al., 2004), the identification of volcanic sulfate spikes within a given area (Parrenin et al., 2012b; Severi et al., 2007) or the hypothesis of synchronous regional deposition of aerosols recorded as ice impurities (Seierstad et al., 2014). In the first case, limitations are associated with the smoothing of atmospheric composition changes through firn air diffusion. In the second case, mismatches may arise through incorrect identification of events in different ice cores.

- Correlation with other well-dated climatic records. In some cases, high-resolution calcite $\delta^{18} \mathrm{O}$ records and precise $\mathrm{U} / \mathrm{Th}$ dates on speleothems have been used to adjust ice core chronologies (Barker et al., 2011; Buizert et al., 2015; Parrenin et al., 2007a). Pinning ice core and speleothem records is attractive to reduce absolute age uncertainties especially during past abrupt climatic events of glacial periods. However, these ex- 
ercises rely on the assumption of simultaneous abrupt climatic changes recorded in ice core (e.g., water isotopes, $\left.\mathrm{CH}_{4}\right)$ and low-latitude speleothem $\delta^{18} \mathrm{O}$ records (mostly reflecting changes in regional atmospheric water cycle). A main limitation of this method lies in the validity of this assumption.

- Modeling of the sedimentation process: snow accumulation, snow densification into ice, air bubbles trapping and ice flow (Goujon et al., 2003; Huybrechts et al., 2007; Johnsen et al., 2001). Glaciological modeling provides a chronology derived from the estimate of the annual layer thickness and, therefore, leads to more realistic event durations when the accumulation history and thinning function are well constrained. A side product of glaciological modeling is the quantification of changes in surface accumulation rates and the quantification of the initial geographical origin of ice. This additional information is necessary to convert measurements of concentrations of chemical species in ice cores into deposition fluxes and to correct ice core records from upstream origin effects (e.g., EPICA community members, 2006; Röthlisberger et al., 2008). Caveats are caused by unknown parameters of such glaciological models, such as amplitude of accumulation change between glacial and interglacial periods, the basal melting or the vertical velocity profile, which have a growing influence at depth.

A common and optimal chronology for several ice cores can be built through the combination of several of these methods in the frame of a probabilistic approach. The first attempts used absolute and orbitally tuned age markers along one ice core to constrain the unknown parameters of an ice flow model (e.g., Parrenin et al., 2001, 2004; Petit et al., 1999). This method had however several limitations. First, the uncertainties associated with the ice flow model could not be taken into account, resulting in underestimated uncertainties. Second, the stratigraphic links between ice cores were not exploited, each ice core was dated separately, resulting in inconsistent chronologies.

A new probabilistic approach based on a Bayesian framework was subsequently introduced. The first tool, Datice, was developed by Lemieux-Dudon et al. (2010a, b). It introduced modeling errors on three canonical glaciological quantities of the dating problem: the accumulation rate, the LID of air bubbles and the thinning function (i.e., ratio between the in situ annual layer thickness on its initial surface vertical thickness). This method starts from a priori (also called "background") scenarios for the three glaciological parameters corresponding to a prior chronology for each ice core. These scenarios, deduced from a modeling of the sedimentation process, are associated with an uncertainty related to the degree of confidence in these prior scenarios. A minimization approach is then applied to find the best compromise between the prior chronological information for each ice core as well as absolute and relative age markers in the ice and in the air phases. This approach has been validated through the Datice tool and applied to build the Antarctic Ice Cores Chronology 2012 (AICC2012), producing coherent ice and air timescales for five different ice cores (Bazin et al., 2013; Veres et al., 2013): EPICA Dome C (EDC), Vostok (VK), Talos Dome (TALDICE), EPICA Dronning Maud Land (EDML) and NorthGRIP (NGRIP). Further developments of Datice were performed to incorporate additional dating constraints such as the depth intervals with known durations and correlation of errors (Bazin et al., 2014). Datice provides an excellent reference for this Bayesian approach. Still, because Datice has been developed over a long-term period with a continuous effort in calculation optimization through methodological improvement, the final code is difficult to access for a non-expert and cannot easily be used as a community tool. We thus identified the need for an open and user-friendly program with a performance similar to Datice but more easily used and implemented by different users within the ice core community.

In this paper, we present a new probabilistic model, IceChrono1, based exactly on the same approach as Datice but with improvements and simplifications in the mathematical, numerical and programming aspects. We first detail the IceChrono1 methodology highlighting the differences to Datice (Sect. 2). We then perform dating experiments described in Sect. 3 using IceChrono1. We first replicate the AICC2012 experiment, and perform four additional experiments to test new functionalities of IceChrono1. The results of these experiments are discussed in Sect. 4. We summarize our main findings in the conclusions, and describe perspectives for future developments of IceChrono in Sect. 5.

\section{Method}

The table in the Appendix B lists all symbols used to describe the IceChrono1 methodology.

\subsection{Method summary}

The true chronology of an ice core, i.e., the ice and air ages at any depth, is a function of three variables (also functions of the depth): the initial accumulation rate (the accumulation rate when and where the particle was at surface), the lock-in depth of the air and the thinning function (the ratio between the thickness of a layer in the ice core to the initial accumulation rate). This is what we call the forward model. These variables are unknown and to find our optimal chronology we estimate them based on

- prior information about their values on each ice core

- chronological observations, such as (see Fig. 1) the ice or air age at a certain depth, the time elapsed between two depths, the synchroneity between two ice or air 


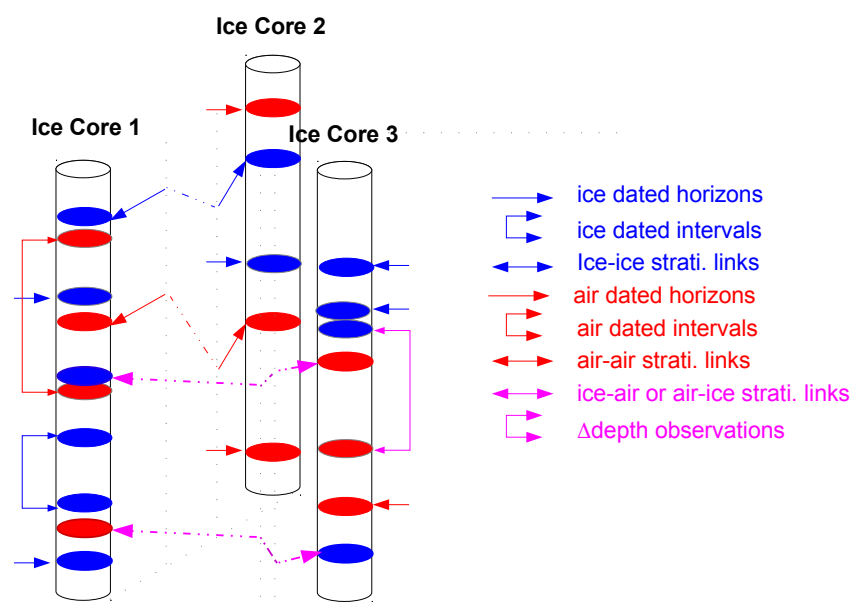

Figure 1. Scheme illustrating the different kinds of observations used to constrain the chronologies of the ice cores in the IceChrono 1 model.

depths within two different ice cores or the depth shift between synchronous ice and air depths within the same ice core.

All these different types of information, mathematically described as probability density functions (PDF), are assumed to be independent and are combined using a Bayesian framework to obtain posterior estimates of the three input variables (accumulation, LID and thinning) and of the resulting chronologies. Uncertainties on the prior estimates and on the observations are further assumed to be Gaussian and the forward model is linearized, which allow using the LevenbergMarquardt (hereafter LM) algorithm (Levenberg, 1944; Marquardt, 1963) to solve this least-squares optimization problem. The philosophy of the method is similar to that of the Datice method (Lemieux-Dudon et al., 2010a, b).

\subsection{The forward model}

For each ice core denoted by its index $k$, given three quantities (initial accumulation rate, air LID and incompressible ice thinning function), the model computes at any depth $z_{k}$ the age for the ice matrix $\chi_{k}$ (in years relative to the drilling date) and the age for the air/hydrates contained in the ice $\psi_{k}$ (which, for simplicity, are assumed unique; we do not consider the age distributions due to gas diffusion and progressive lock in with depth) using the following formulas:

$\chi_{k}\left(z_{k}\right)=\int_{0}^{z_{k}} \frac{D_{k}\left(z^{\prime}{ }_{k}\right)}{a_{k}\left(z_{k}^{\prime}\right) \tau_{k}\left(z_{k}^{\prime}\right)} \mathrm{d} z^{\prime}{ }_{k}$,
$\psi_{k}\left(z_{k}\right)=\chi_{k}\left(z_{k}-\Delta d\left(z_{k}\right)\right)$,

$\int_{z_{k}-\Delta d_{k}\left(z_{k}\right)}^{z_{k}} \frac{D\left(z_{k}^{\prime}\right)}{\tau\left(z_{k}^{\prime}\right)} \mathrm{d} z^{\prime}{ }_{k} \approx \int_{0}^{l_{k}\left(z_{k}\right) D_{k}^{\mathrm{firm}}\left(z_{k}\right)} \frac{1}{\tau_{k}\left(z_{k}^{\mathrm{ie}}\right)} \mathrm{d} z^{\text {ie }}{ }_{k}$, where $z_{k}$ is the depth in the ice core (0 is the surface), $D_{k}$ is the relative density of the material with respect to pure ice (treated as a known time series), $a_{k}$ is the initial accumulation rate (expressed in meters in ice equivalent per year), $\tau_{k}$ is the incompressible thinning function, $\Delta d_{k}$ is the $\Delta$ depth (the depth shift between synchronous events in the ice and air phases, taken as dependent on the air depth, by convention), $l_{k}$ is the LID (taken as dependent on the air depth, by convention), $D_{k}^{\text {firn }}$ is the average relative density of the firn when depth $z_{k}$ was at LID (treated as a known time series, dependent on the air depth, by convention) and $z_{k}^{\mathrm{ie}}$ is the ice equivalent depth:

$z_{k}^{\mathrm{ie}}=\int_{0}^{z_{k}} D_{k}\left(z_{k}^{\prime}\right) \mathrm{d} z_{k}^{\prime}$

Note that in our convention inherited from glaciology, accumulation $a_{k}$ is expressed in ice equivalent per year and the thinning function $\tau_{k}$ is expressed with respect to this iceequivalent accumulation rate, hence the appearance of $D_{k}$ in Eq. (1). We used this convention because most of the ice flow models, which give prior estimates on the thinning function (see below), only consider pure ice; i.e., they assume the snow is instantaneously densified into ice when it falls at the surface of the ice sheet.

The first equation integrates along the depth axis the number of annual layers per meter from the surface. The second equation means that the air age at depth $z_{k}$ is equal to the ice age at depth $z_{k}-\Delta d_{k}$. This is the definition of $\Delta$ depth. The third equation means that if one virtually unthins a depth interval between an ice depth and the synchronous air depth, one gets the unthinned lock-in depth in ice equivalent (ULIDIE; see Fig. 2). The right-hand side of the third equation is an approximation, since we assume that the incompressible thinning function in the firn is constant through time. But because the incompressible thinning function is usually very close to 1 in the firn (the ice flow is almost negligible in the first $\sim 100 \mathrm{~m}$ of the ice sheet), this assumption is almost verified. No other approximation is introduced in this set of equations. However, there are additional approximations in the sedimentation models that provide the values of $a_{k}, l_{k}$ and $\tau_{k}$ and we will discuss the errors linked to these approximations below.

Let us assume we have prior estimates of the accumulation (denoted $a_{k}^{\mathrm{b}}$ ), of the LID (denoted $l_{k}^{\mathrm{b}}$ ) and of the ice thinning function (denoted $\tau_{k}^{\mathrm{b}}$ ). The prior information can come from a combination of models and data. Typically, ice flow models can give an estimate of the thinning function, ice $\delta \mathrm{D}$ and $\delta^{18} \mathrm{O}$ are often used to deduce accumulation rates (e.g., Parrenin et al., 2007b), and firn densification models or $\delta^{15} \mathrm{~N}$ measurements in air bubbles are used to deduce the LID and the average firn relative density. We now define logarithmic correction functions:

$c_{k}^{a}=\ln \left(a_{k} / a_{k}^{\mathrm{b}}\right)$, 


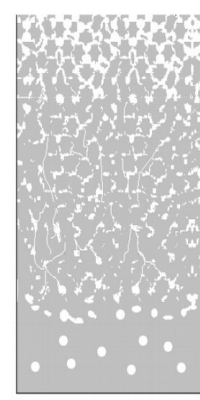

Lock-In Depth

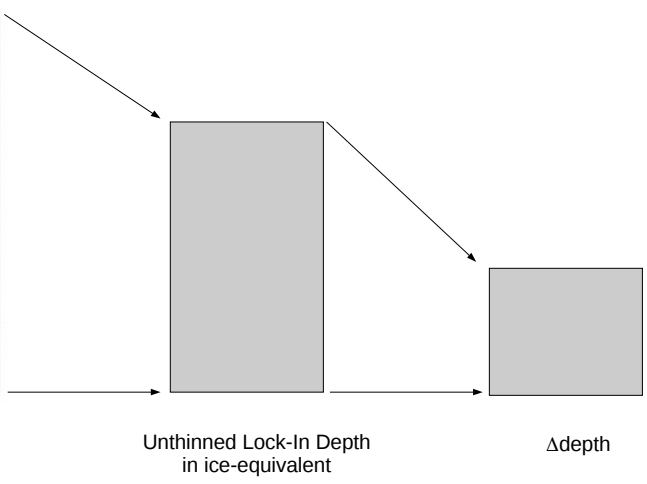

Figure 2. Scheme of different representations of a firn column. (Left) When the firn column is at surface, its height is equal to the lock-in depth. (Middle) If one virtually converts the firn column into cumulated ice-equivalent accumulations, one gets the unthinned lock-in depth in ice equivalent (ULIDIE). (Right) When the firn column is buried down into the ice sheet and encounters vertical thinning, its height decreases to $\Delta$ depth.

$c_{k}^{l}=\ln \left(l_{k} / l_{k}^{\mathrm{b}}\right)$,

$c_{k}^{\tau}=\ln \left(\tau_{k} / \tau_{k}^{\mathrm{b}}\right)$,

so that the forward model effectively takes as inputs the three logarithmic correction functions instead of the three raw glaciological quantities. This change of variable allows us to transform Jeffreys variables into Cartesian variables (Tarantola, 2005) so as to express our problem into a leastsquares problem and will allow us to reduce the number of variables to be inverted (see below).

The three prior quantities $a_{k}^{\mathrm{b}}, l_{k}^{\mathrm{b}}$ and $\tau_{k}^{\mathrm{b}}$ as well as the relative density $D_{k}$ are discretized onto the same fine-depth grid: $z_{k, i}$ ( $i$ being the index of the node), called the age equation grid, which may not be regular. This allows us to compute prior ice and air age scales. Then, we discretize the correction functions $c_{k}^{a}, c_{k}^{l}$ and $c_{k}^{\tau}$ onto coarser grids, which also may not be regular and which depend on the age for $a$ and $l$ and on the depth for $\tau: t_{k, i}^{a}, t_{k, i}^{l}, z_{k, i}^{\tau}$ (i being the index of the node). We note $\boldsymbol{C}_{k}^{a}=\left(c_{k, i}^{a}\right)_{i}, \boldsymbol{C}_{k}^{l}=\left(c_{k, i}^{l}\right)_{i}$ and $\boldsymbol{C}_{k}^{\tau}=\left(c_{k, i}^{\tau}\right)_{i}$ as the correction vectors. These grids are coarser than the age grid to limit the number of variables to be inverted. The correction functions are then transferred to the age equation grid using a linear interpolation (for $a$ and $l$, this step requires using the prior age scale). This allows us to compute the three glaciological quantities $a_{k}, l_{k}$ and $\tau_{k}$ onto the age equation grid. We note $\boldsymbol{X}$ as the state vector, that is, the vector containing all the correction vectors on the coarse grids for all the ice core sites.

Equation (1) for the ice age is solved first. Then, Eq. (3) for $\Delta$ depth is solved, which allows us to deduce the air age from Eq. (2). To solve Eq. (3), we first integrate $D_{k} / \tau_{k}$ from the surface down to every depth in the age equation grid; i.e., we have a correspondence table between real depths and unthinned-ice-equivalent (UIE) depths. Then, for every air real depth in the age equation grid, we obtain the air UIE depth from the correspondence table. We then subtract the second member of Eq. (3) from this air UIE depth to get the ice UIE depth. Finally, we use the correspondence table to obtain the ice real depth and the $\Delta$ depth. When we need to compute the ice age, air age or $\Delta$ depth at depths which are not nodes of the age equation grid (for example when comparing the model with observations, see below), we use a linear interpolation.

\subsection{The cost function}

In probabilistic terms, one combines different sources of information which are assumed to be independent (the prior and the observations) and one looks for the most probable scenario, i.e., the most probable $\boldsymbol{X}$ (Tarantola, 2005). In mathematical terms, it corresponds to multiplying the PDFs of the prior and of the observations, the result of this multiplication being called the likelihood function $L$. Here, we assumed the PDFs to be independent multivariate Gaussian distributions. The posterior likelihood function $L$ can therefore be written as

$L=\exp \left(-\frac{1}{2} J\right)$

where $J$, the cost function, is a sum of least-squares terms, each corresponding to an independent multivariate Gaussian PDF. Maximizing the likelihood function therefore corresponds to minimizing the cost function. In this case, we assume the information on each ice core and on each ice core pair to be independent. The cost function can therefore be written as a sum of terms:

$J=\sum J_{k}+\sum J_{k, m}$,

where $J_{k}$ is the term related to ice core number $k$ and $J_{k, m}$ is the term related to the ice core pair $(k, m)$.

$J_{k}$ measures the misfit of the model with respect to the prior and the observations for ice core number $k$. It is written as the sum of independent terms:

$J_{k}=J_{k}^{a}+J_{k}^{l}+J_{k}^{\tau}+J_{k}^{\mathrm{ih}}+J_{k}^{\mathrm{ah}}+J_{k}^{\mathrm{ii}}+J_{k}^{\mathrm{ai}}+J_{k}^{\Delta d}$,

where $J_{k}^{a}, J_{k}^{l}$ and $J_{k}^{\tau}$ are the prior terms for respectively $a$, $l$ and $\tau, J_{k}^{\text {ih }}$ is linked to ice-dated horizons, $J_{k}^{\text {ah }}$ is linked to air-dated horizons, $J_{k}^{\mathrm{ii}}$ is linked to ice intervals with known duration, $J_{k}^{\text {ai }}$ is linked to air intervals with known duration and $J_{k}^{\Delta d}$ is linked to $\Delta$ depth observations.

$J_{k, m}$ measures the misfit of the model with respect to the stratigraphic links in between ice cores $k$ and $m$. It is the sum of four independent terms:

$J_{k, m}=J_{k, m}^{\mathrm{ii}}+J_{k, m}^{\mathrm{aa}}+J_{k, m}^{\mathrm{ia}}+J_{k, m}^{\mathrm{ai}}$,

where $J_{k, m}^{i i}$ is linked to ice-ice stratigraphic links, $J_{k, m}^{\mathrm{aa}}$ is linked to air-air stratigraphic links, $J_{k, m}^{\mathrm{ia}}$ is linked to ice-air 
stratigraphic links and $J_{k, m}^{\text {ai }}$ is linked to air-ice stratigraphic links.

We first describe the prior terms:

$J_{k}^{a}=\left(\boldsymbol{R}_{k}^{a}\right)^{\mathrm{T}}\left(\mathbf{P}_{k}^{a}\right)^{-1}\left(\boldsymbol{R}_{k}^{\mathrm{a}}\right)$,

$J_{k}^{l}=\left(\boldsymbol{R}_{k}^{l}\right)^{\mathrm{T}}\left(\mathbf{P}_{k}^{l}\right)^{-1}\left(\boldsymbol{R}_{k}^{1}\right)$,

$\boldsymbol{J}_{k}^{\tau}=\left(\boldsymbol{R}_{k}^{\tau}\right)^{\mathrm{T}}\left(\mathbf{P}_{k}^{\tau}\right)^{-1}\left(\boldsymbol{R}_{k}^{\tau}\right)$,

where $\mathbf{P}_{k}^{a}, \mathbf{P}_{k}^{l}, \mathbf{P}_{k}^{\tau}$ are the correlation matrices of the prior and where $\boldsymbol{R}_{k}^{a}, \boldsymbol{R}_{k}^{l}, \boldsymbol{R}_{k}^{\tau}$ are the residual vectors:

$$
\begin{aligned}
\boldsymbol{R}_{k}^{a} & =\left(\frac{c_{k, i}^{a}}{\sigma_{k, i}^{a}}\right)_{i}, \\
\boldsymbol{R}_{k}^{l} & =\left(\frac{c_{k, i}^{l}}{\sigma_{k, i}^{l}}\right)_{i}, \\
\boldsymbol{R}_{k}^{\tau} & =\left(\frac{c_{k, i}^{\tau}}{\sigma_{k, i}^{\tau}}\right)_{i},
\end{aligned}
$$

with $\left(\sigma_{k, i}^{a}\right)_{i},\left(\sigma_{k, i}^{l}\right)_{i}$, and $\left(\sigma_{k, i}^{\tau}\right)_{i}$ the standard deviation vectors for respectively the prior accumulation, LID, and thinning function. These three terms $J_{k}^{a}, J_{k}^{l}$ and $J_{k}^{\tau}$ bring the "glaciological constraints" of the problem given by the sedimentation models. For example, they ensure that the optimum values for $a, l$ and $\tau$ will be close to the prior values and also that their rates of change with respect to depth will be close to the rates of change of the prior values. That means the model giving the prior scenario for the accumulation, the LID, and the thinning function should have a quantified error. The correlation matrices define the correlation of uncertainties of the correction functions at different depth levels or ages. In practice, the IceChrono code is flexible, and any standard deviation vector and correlation matrix can be prescribed.

The other terms of $J_{k}$ are simply comparisons to observations, assumed independent:

$$
\begin{aligned}
& \boldsymbol{R}^{\mathrm{T}} \mathbf{P}^{-1} \boldsymbol{R}, \\
& \boldsymbol{R}=\left(\frac{m_{i}-o_{i}}{\sigma_{i}}\right)_{i},
\end{aligned}
$$

where $\boldsymbol{R}$ is the residual vector, $\left(m_{i}\right)_{i}$ are the model realizations of the observations, $\left(o_{i}\right)_{i}$ are the observations, $\left(\sigma_{i}\right)_{i}$ are their standard deviations and $\mathbf{P}$ is their correlation matrix. These terms are given in more details in the Appendix. Again, the IceChrono model is flexible, and whatever standard deviation vectors and correlation matrices can be prescribed.

For $J_{k}^{\text {ih }}$ and $J_{k}^{\text {ah }}$, one prescribes depth, age and standard deviation of ice- and air-dated horizons and the correlation matrix. For $J_{k}^{\mathrm{ii}}$ and $J_{k}^{\mathrm{ai}}$, one prescribes the top depth, bottom depth, duration and standard deviation of ice and air intervals with known durations and the correlation matrix. For
$J_{k}^{\Delta d}$, one prescribes air depth, $\Delta$ depth and standard deviation of $\Delta$ depth markers and the correlation matrix. For $J_{k, m}^{\mathrm{ii}}$, $J_{k, m}^{\mathrm{aa}}, J_{k, m}^{\mathrm{ia}}, J_{k, m}^{\mathrm{ai}}$, one prescribes the depth in the first core, the depth in the second core and a standard deviation in years of ice-ice, air-air, ice-air or air-ice stratigraphic links and the correlation matrix.

The determination of the standard deviation vectors and of the correlation matrices of the prior (resp. the observations) can be a difficult problem which requires an in-depth analysis of the methods used to determine the prior (resp. the observations).

\subsection{Optimization}

We now try to find the $\boldsymbol{X}$ input vector that minimizes the cost function defined in Eq. (9). This least-squares optimization problem is solved using a standard LM algorithm (Levenberg, 1944; Marquardt, 1963). The LM algorithm iteratively converges toward a minimum of the cost function and stops when a convergence criteria is met. To converge, the LM algorithm uses the Jacobian of the observation operator (the operator which output all the residuals from the $\boldsymbol{X}$ vector), which is here calculated using a finite difference approach. The LM algorithm gives as a result the optimized values of the model input variables vector $\boldsymbol{X}^{\mathrm{opt}}$ (containing the correction functions defined on the coarse grids) as well as an approximate estimation of its a posteriori error covariance matrix $\mathbf{C}^{X}$ : the algorithm approximates the model by its linear tangent around the solution.

We note $\boldsymbol{G}(\boldsymbol{X})$ as the forward model vector containing all the variables for which we want to compute the optimal values and the uncertainties (in particular the ice and air ages on the age equation grids). The optimal model is therefore $\boldsymbol{G}\left(\boldsymbol{X}^{\mathrm{opt}}\right)$. From the model Jacobian $\mathbf{G}^{\prime}$ at $\boldsymbol{X}^{\mathrm{opt}}$, which is calculated using a numerical finite difference approach, and from $\mathbf{C}^{X}$, one can compute an approximated value of the error covariance matrix for the model as

$\mathbf{C}^{G} \approx\left(\mathbf{G}^{\prime}\right) \mathbf{C}^{X}\left(\mathbf{G}^{\prime}\right)^{\mathrm{T}}$.

The diagonal elements of $\mathbf{C}^{G}$ give the variance of the model's variables. In practice, the matrix $\mathbf{C}^{G}$ is never completely formed to limit the memory size of the program. Only diagonal bloc elements corresponding to a particular variable (e.g., ice age) on a particular ice core are calculated.

To ensure that the LM algorithm converges toward a global minimum of the cost function, we initialize it with different initial conditions $\boldsymbol{X}_{0}$ all taken randomly according to the prior density of probability. We then check that the LM algorithm always converges toward the same solution.

\subsection{Programming aspects}

IceChrono 1 is entirely coded in the python v 2 programming language. IceChrono1 both resolves the optimization problem and provides figures to display the results. The core of 
the code is entirely separated from the experiment setup directory which also contains the results of the run and which is composed of general parameter files, a directory for each ice core (which contains the parameters and observations for the given ice core) and a directory for each ice core pair (which contains the observations for the given ice core pair). Only a basic understanding of python and an understanding of the structure of the experiment setup directory are needed to run IceChrono1. A detailed tutorial on how to use the IceChrono1 software is also available within the code.

The core of the code is about 1000 lines long (including white lines and comments) and is built using an objectoriented paradigm. In such an object oriented language, apart for the classical type of variables (integer, real, characters, etc.), one can define his or her own classes of objects, containing variables and functions. In IceChrono1, a class exists for the ice core objects. It contains the variables related to this ice core: the age equation grid, the correction function grids, the prior scenarios and their associated standard deviations and correlation matrices, the relative density profile, the correction functions, the observations and their associated standard deviations and correlation matrices and the resulting calculated variables (accumulation, LID and thinning, ice and air ages, $\Delta$ depth, ice and air layer thickness, etc.). It also contains functions performing the following tasks: the initialization of the ice core (i.e., reading of the parameters, priors and observations), the calculation of the age model, the calculation of the residuals, the calculation of the forward model Jacobian, the calculation of the standard deviations, the construction of the figures (for ice age, air age, accumulation, LID, thinning, ice layer thickness and $\Delta$ depth) and the saving of the results. A class also exists for the ice core pair objects. It contains all the stratigraphic links and their associated standard deviation and correlation matrices relative to this ice core pair. It also contains functions that perform the following tasks: the initialization of the ice core pair, the calculation of the residuals, and the construction of the figures (for ice-ice links, air-air links, ice-air links and air-ice links). The main program is kept as simple and straightforward as possible.

We used the LM algorithm as implemented in the leastsq function from the scipy.optimize library, which also provides an automatic convergence criteria. It does not try to minimize directly the cost function but rather a residual vector, the components of this residual vector being supposed independent from each other and with a unit standard deviation. Inside each term of the cost function

$$
\boldsymbol{R}^{\mathrm{T}} \mathbf{P}^{-1} \boldsymbol{R}
$$

We allow defining a correlation matrix $\mathbf{P}$ so that the residuals can actually be correlated. We thus used a Cholesky decomposition of $\mathbf{P}$,

$\mathbf{P}=\mathbf{P}^{1 / 2} \mathbf{P}^{1 / 2}$, and a change of variable,

$\boldsymbol{R}^{\prime}=\left(\mathbf{P}^{1 / 2}\right)^{-1} \boldsymbol{R}$,

to transform the residual vector into a vector composed of independent variables with unit standard deviation. The associated term of the cost function can now be written as

$\left(\boldsymbol{R}^{\prime}\right)^{\mathrm{T}} \boldsymbol{R}^{\prime}$

that is, the residuals are now independent and with a unit standard deviation.

\section{Dating experiments}

In this section, we describe the setups and the results of various dating experiments.

\subsection{Standard AICC2012 experiment}

IceChrono1 is similar in scope to the Datice model (Lemieux-Dudon et al., 2010a, b). Datice has been used to build AICC2012, the most recent official chronology for the four Antarctic ice cores EPICA Dome C (EDC), Vostok (VK), Talos Dome (TALDICE), EPICA Dronning Maud Land (EDML) and the Greenland ice core NorthGRIP (NGRIP) (Bazin et al., 2013; Veres et al., 2013). The AICC2012 experiment was based on a previous experiment (Lemieux-Dudon et al., 2010a) on three Antarctic ice cores (EDC, VK, EDML) and one Greenland ice core (NGRIP) but with updated chronological information. All chronological information is available in the supplementary material of Bazin et al. (2013) and Veres et al. (2013). This experiment integrates orbital tuning constraints based on the $\delta^{18} \mathrm{O}_{\mathrm{atm}}, \mathrm{O}_{2} / \mathrm{N}_{2}$ and air content records (Bazin et al., 2013; Dreyfus et al., 2007, 2008; Landais et al., 2012; Lipenkov et al., 2011; Raynaud et al., 2007; Suwa and Bender, 2008), layer counting on NGRIP back to $60 \mathrm{kyr}$ B1950 (Svensson et al., 2008, and references therein), a tephra layer (Narcisi et al., 2006) dated independently at $93.2 \pm 4.4 \mathrm{kyr}$ B1950 (Dunbar et al., 2008), the Laschamp geomagnetic excursion at $40.65 \pm 0.95 \mathrm{kyr}$ B 1950 (Singer et al., 2009) and the Brunhes-Matuyama geomagnetic reversal at $\sim 780.3 \pm 10 \mathrm{kyr} \mathrm{B} 1950$ and its precursor at $798.3 \pm 10 \mathrm{kyr}$ B1950 (Dreyfus et al., 2008) identified in the ${ }^{10} \mathrm{Be}$ records (Raisbeck et al., 2006, 2007; Yiou et al., 1997), a Holocene ${ }^{10} \mathrm{Be}$-dendrochronology tie point on Vostok at $7.18 \pm 0.1 \mathrm{kyr}$ B1950 (Bard et al., 1997; Raisbeck et al., 1998), $\Delta$ depth observations at NGRIP obtained by comparing the $\delta^{18} \mathrm{O}_{\text {ice }}$ and $\delta^{15} \mathrm{~N}$ records (Capron et al., 2010; Huber et al., 2006; Landais et al., 2004, 2005), air synchronization tie points using the $\mathrm{CH}_{4}$ records (Buiron et al., 2011; Capron et al., 2010; Landais et al., 2006; Lemieux-Dudon et al., 2010a; Loulergue et al., 2007; Schilt et al., 2010; Schüpbach et al., 2011) the $\delta^{18} \mathrm{O}$ records (Bazin et al., 2013) and 
ice synchronization tie points using the volcanic records (Parrenin et al., 2012b; Severi et al., 2007, 2012; Svensson et al., 2013; Udisti et al., 2004; Vinther et al., 2013) and the ${ }^{10} \mathrm{Be}$ records (Raisbeck et al., 2007).

In this AICC2012-VHR (AICC2012 very high resolution) experiment, IceChrono1 is tested on the exact same setup, using the same observations and the same definition of the prior information as Datice was used. Only one aspect is modified: in AICC2012, the prior correlation matrices for the thinning function and LID are supposed to have an across-diagonal Gaussian decrease in amplitude. This Gaussian shape leads to a too high correlation for neighboring points. As a consequence, these matrices are numerically very difficult to invert (with a poor conditional state). We therefore opt for correlation matrices with an across-diagonal linear decrease in amplitude. We use regular grids with a time step of $1 \mathrm{kyr}$ for the accumulation and LID correction functions and with 1001 nodes for the thinning correction functions. For the age equation grid, we use a step of $0.55 \mathrm{~m}$ for EDC, $1 \mathrm{~m}$ for VK, $1 \mathrm{~m}$ for TALDICE, $1 \mathrm{~m}$ for EDML and $1 \mathrm{~m}$ for NGRIP.

The IceChrono1 AICC2012-VHR experiment results are provided as a Supplement. This also includes all the figures produced by the IceChrono1 model.

\subsection{Sensitivity test to resolution}

In this experiment AICC2012-V2HR (AICC2012 very very high resolution), we test the impact of the resolution of the correction functions on the results of the optimization. We use exactly the same setup as for the AICC2012-VHR experiment, except for the resolution of the correction functions which is twice as high: we use regular grids with a time step of $0.5 \mathrm{kyr}$ for the accumulation and LID correction functions and with 2001 nodes for the thinning correction functions.

Figure 3 compares the AICC2012-V2HR and AICC2012VHR experiments for the ice age. The differences are minor and do not exceed $60 \mathrm{yr}$.

Figure 4 compares the resulting chronologies for the EDC ice core using the IceChrono1 (experiment AICC2012V2HR) and Datice codes, as well as their uncertainties. Note that we did not use the official AICC2012 uncertainties for the ice and air ages (Bazin et al., 2013; Veres et al., 2013), but rather the raw uncertainties as calculated by the Datice code. The difference in both chronologies is less than $200 \mathrm{yr}$ for the last $600 \mathrm{kyr}$ and less than $500 \mathrm{yr}$ all along the record. The uncertainties also show comparable shapes. We remark a few noticeable differences, though. There is a high frequency noise in the air age difference, especially for the most recent periods. This is due to the fact that the $\delta^{15} \mathrm{~N}$ data which are used to infer the LID contain high-frequency variations and that Datice uses a higher resolution than IceChrono for these periods $(1.65 \mathrm{~m}$ for $\mathrm{EDC}, 2 \mathrm{~m}$ for $\mathrm{VK}, 3 \mathrm{~m}$ for EDML, $1 \mathrm{~m}$ for TALDICE and $1 \mathrm{~m}$ for NGRIP). For the last $60 \mathrm{kyr}$, the uncertainties are almost always smaller in Datice than in IceChrono for the ice and almost always smaller in

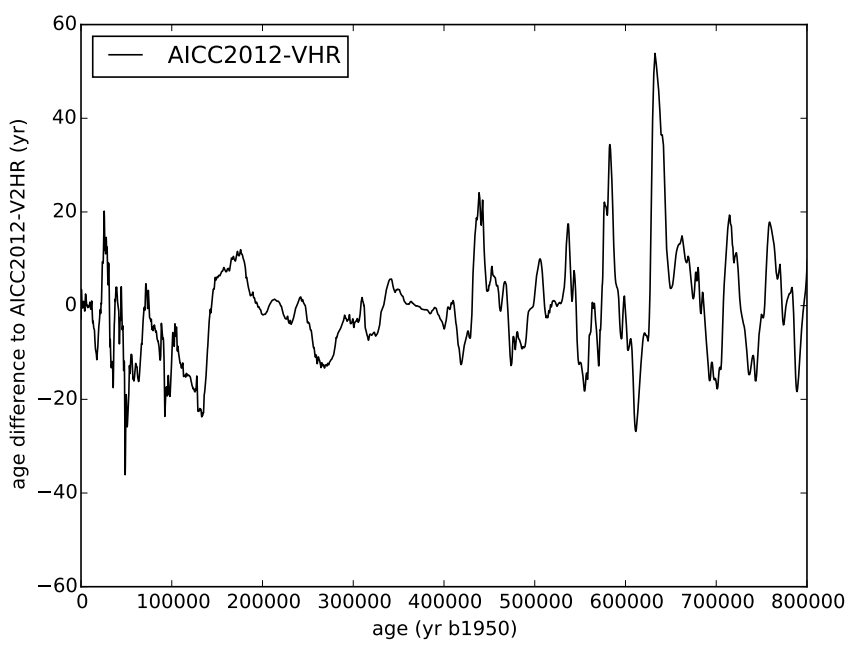

Figure 3. Sensitivity of the AICC2012-like experiment to a change of resolution of the correction functions. The black line is the age difference between the AICC2012-V2HR and AICC2012-VHR experiments (see text).

IceChrono than in Datice for the air ages. For example, between 15 and $60 \mathrm{kyr}$ B1950, the uncertainty on the air age often decreases below $1000 \mathrm{yr}$ in IceChrono1 but never in Datice. Also, the uncertainties of Datice are smaller in the ice phase than in the air phase.

\subsection{Test experiment for ice intervals with known durations}

We now perform a simplified dating experiment to test the inclusion of ice intervals with known durations. This is a new type of observation introduced in IceChrono, not available in the initial version of Datice (Lemieux-Dudon et al., 2010a, b) and not used in the AICC2012 experiment. It has only recently been developed in Datice (Bazin et al., 2014). This experiment is called "test-ice-intervals-with-known-durations". The experiment only contains the NGRIP ice core. The resolution chosen for the correction functions is $200 \mathrm{yr}$ for the accumulation and LID correction functions and 501 nodes for the thinning correction function.

The prior accumulation is deduced directly from the deuterium content of the ice using an exponential relationship:

$a^{\mathrm{b}}=a^{0} \exp \left(8 \beta \Delta \delta^{18} \mathrm{O}\right)$,

where $a^{0}=0.256$ ice $\mathrm{m} \mathrm{yr}^{-1}$ and $\beta=0.0193$. The accumulation covariance matrix is defined by a uniform variance value of $20 \%$ and with a correlation matrix with an acrossdiagonal linear decrease duration of $4000 \mathrm{yr}$. The prior thinning is deduced using the so-called pseudo-steady assumption (Parrenin et al., 2006):

$\tau^{\mathrm{b}}=(1-\mu) \omega+\mu$, 

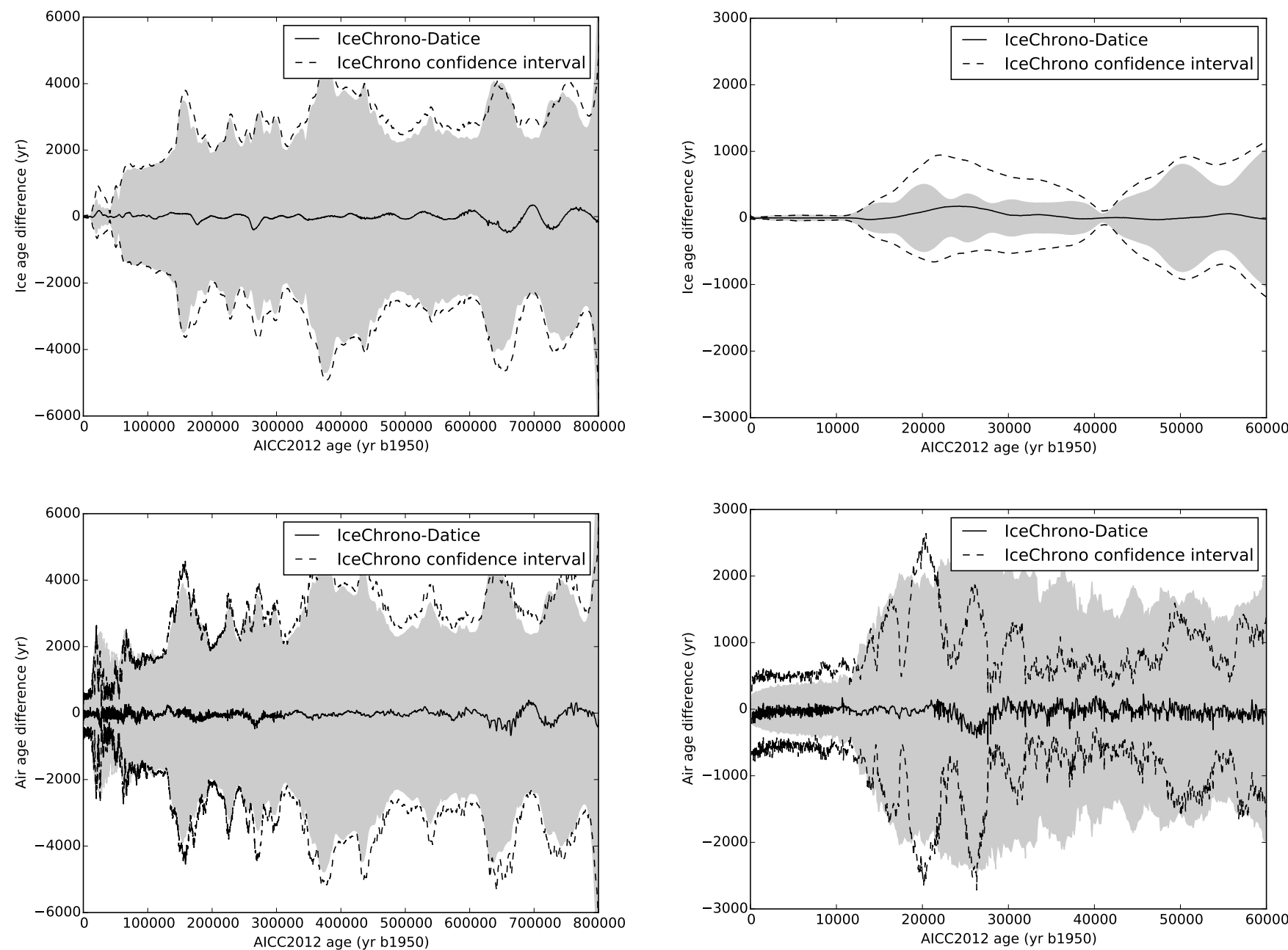

Figure 4. Comparison of IceChrono and Datice chronologies of the EDC ice core in the AICC2012 experiment. IceChrono is the black plain line and its standard deviation is the black dashed line. The AICC2012 standard deviation is represented by the grey area. (top) Ice chronologies. (bottom) Air chronologies.

with $\mu=11 \%$ being the ratio between melting and accumulation assumed constant through time and with $\omega$ being the flux-shape function (Parrenin and Hindmarsh, 2007), defined using a Lliboutry analytical model (Lliboutry, 1979),

$\omega=1-\frac{p+2}{p+1}(1-\zeta)+\frac{1}{p+1}(1-\zeta)^{p+2}$,

with $p=-0.61$. The covariance matrix of the thinning function is defined as a variance, which is assumed linearly related to the ice-equivalent depth $z^{\text {ie }}$ :

$\sigma^{\tau}=k \frac{z^{\mathrm{ie}}}{H^{\mathrm{ie}}}$,

where $H^{\text {ie }}$ is the ice-equivalent ice thickness and $k=0.5$. The value of $a^{0}, \beta, \mu$ and $p$ were adjusted to obtain a good

Figure 5. Comparison of IceChrono and Datice chronologies of the EDC ice core in the AICC2012 experiment, for the last $60 \mathrm{kyr}$. IceChrono is the black plain line and its standard deviation is the black dashed line. The AICC2012 standard deviation is represented by the grey area. (top) Ice chronologies. (bottom) Air chronologies.

fit with the layer-counted GICC05 (Svensson et al., 2008) age markers sampled every $5 \mathrm{kyr}$ along the core.

Here we include only one type of observations, ice intervals with known durations, which result from the layercounted GICC05 chronology (Svensson et al., 2008, and references therein) covering the last $60 \mathrm{kyr}$. This information is sampled every $1 \mathrm{kyr}$. The standard deviation of each observation on every $1 \mathrm{kyr}$ interval is taken as half the variation of the maximum counting error (MCE) on this interval. All observations are assumed independent, i.e., the error on one $1 \mathrm{kyr}$ interval is not correlated with the error on another $1 \mathrm{kyr}$ interval.

The NGRIP ice age results of IceChronol on this optimization experiment are plotted in Fig. 6. As expected, the timescale is tightly constrained by the GICC05 ice intervals with known durations down to $60 \mathrm{kyr}$. The uncertainty of the 


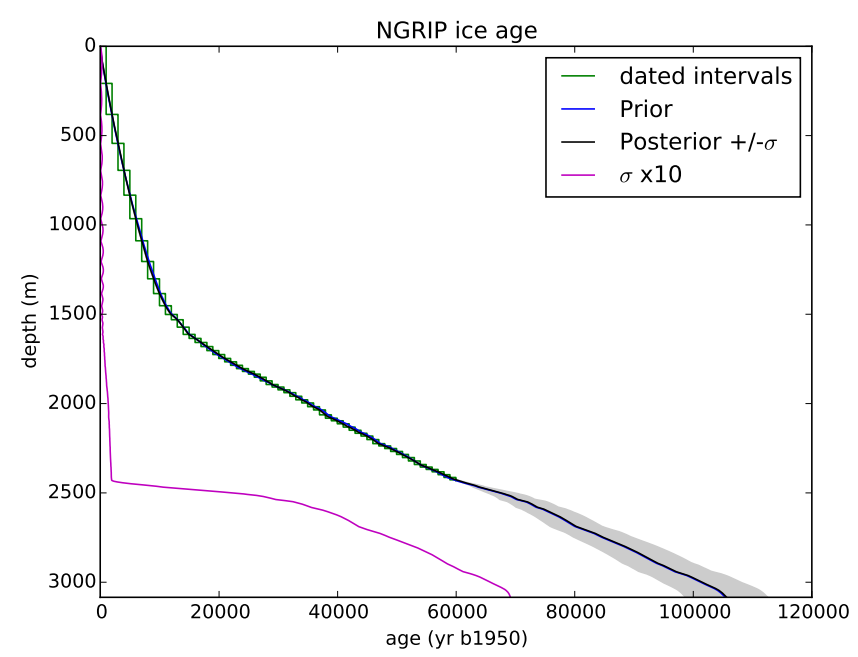

Figure 6. Experiment test-ice-intervals-with-known-durations. NGRIP prior (blue) and posterior (black) chronologies and the posterior confidence interval (grey area) when using independent 1 kyr long intervals with known durations from the GICC05 layercounted timescale (green rectangles; Svensson et al., 2008). The $1 \sigma$ uncertainty of the posterior timescale is also shown on the left (pink). This figure is automatically produced by IceChrono1.

optimized timescale is smaller than half the MCE: for example, at $60 \mathrm{kyr}$ B 1950, the uncertainty of the optimized age scale is $230 \mathrm{yr}$ while half the MCE is $1300 \mathrm{yr}$. This is because the MCE is cumulative while the uncertainties of the $1 \mathrm{kyr}$ long intervals with known durations are assumed to be independent and thus tend to cancel out. Indeed, the squared standard deviation of the sum of independent Gaussian variables is the sum of the squared standard deviation of the independent Gaussian variables. Beyond $60 \mathrm{kyr}$, when there are no ice interval constraints anymore, the uncertainty of the optimized age scale then increases quickly to reach $\sim 7 \mathrm{kyr}$ at the bottom of the core.

\subsection{Test experiment for correlated errors of observations}

We now perform a simplified dating experiment to test the inclusion of correlated uncertainties. This is a new functionality in IceChrono with respect to the first version of Datice (Lemieux-Dudon et al., 2010a, b) and which has not been used in the AICC2012 experiment. It has only recently been developed in Datice (Bazin et al., 2014). This experiment is called "test-ice-intervals-with-known-durationswith-correlation". Again, this experiment contains only the NGRIP ice core. The resolution chosen for the correction functions is $200 \mathrm{yr}$ for the accumulation and LID correction functions and 501 nodes for the thinning correction function.

The prior information is exactly the same as the previous experiment. Only one type of observations is included: ice intervals with known durations. Again, this information comes from the layer-counted timescale GICC05 (Svensson et al., 2008 , and references therein) and is sampled every $1 \mathrm{kyr}$. The standard deviation of each observation on every $1 \mathrm{kyr}$ interval is taken as half the variation of the MCE on this interval. Contrary to the previous experiment, the observations are not assumed independent: the correlation matrix is assumed to contain ones on its diagonal and 0.5 outside of it.

The NGRIP ice age results of IceChronol on this optimization experiment are plotted in Fig. 7. As expected, the timescale is well constrained by the GICC05 intervals with known durations of observations down to $60 \mathrm{kyr}$ and explodes beyond this age. Contrary to the previous experiment, the uncertainties of the intervals with known durations do not cancel out since they are correlated. Indeed, the standard deviation of the sum of completely dependent Gaussian variable is the sum of the standard deviations of the completely dependent Gaussian variables. As a consequence, the a posteriori uncertainty of the optimized timescale increases to $\sim 900 \mathrm{yr}$ at $60 \mathrm{kyr}$, comparable to a MCE equal to $\sim 2600 \mathrm{yr}$ at this age.

\subsection{Test experiment for air intervals with known durations}

We now perform a simplified dating experiment to test the inclusion of air intervals with known durations, which is a new type of observation in IceChrono with respect to the first version of Datice (Lemieux-Dudon et al., 2010a, b), not used in AICC2012. This experiment is called test-air-intervals-withknown-durations. The experiment contains only the EDC ice core. The resolution chosen for the correction functions is $200 \mathrm{yr}$ for the accumulation and LID correction functions and 501 nodes for the thinning correction function. We perform the dating experiment only down to a depth of $1400 \mathrm{~m}$ (age of $\sim 100 \mathrm{kyr} \mathrm{B1950)}$.

The prior information is the same as for the AICC2012VHR experiment. We include observations as air intervals with known durations. This information comes from the layer-counted timescale GICC05 of NGRIP (Svensson et al., 2008, and references therein) and is transferred onto EDC through a NGRIP- $\delta^{18} \mathrm{O}_{\text {ice }} / \mathrm{EDC}-\mathrm{CH}_{4}$ synchronization. Each air-dated interval is defined by the onsets of DO events (including the Younger Dryas/Preboreal - YD/PB - transition) down to DO12 ( 46.8 kyr B1950). The top and bottom depths of the air intervals with known durations are directly taken from fast $\mathrm{CH}_{4}$ transitions (Loulergue et al., 2007, Table 2). The durations of the air intervals with known durations are directly taken from the GICC05 timescale (Svensson et al., 2008, Table 1). The standard deviation of each interval observation is taken as half the MCE on this interval. The observations are assumed uncorrelated: the correlation matrix is assumed to be equal to the identity matrix. We also add the GICC05 age of the $\mathrm{CH}_{4} \mathrm{YD} / \mathrm{PB}$ transition as an airdated horizon. This is equivalent to using an air interval from the LID to the $\mathrm{CH}_{4} \mathrm{YD} / \mathrm{PB}$ transition with known duration, 


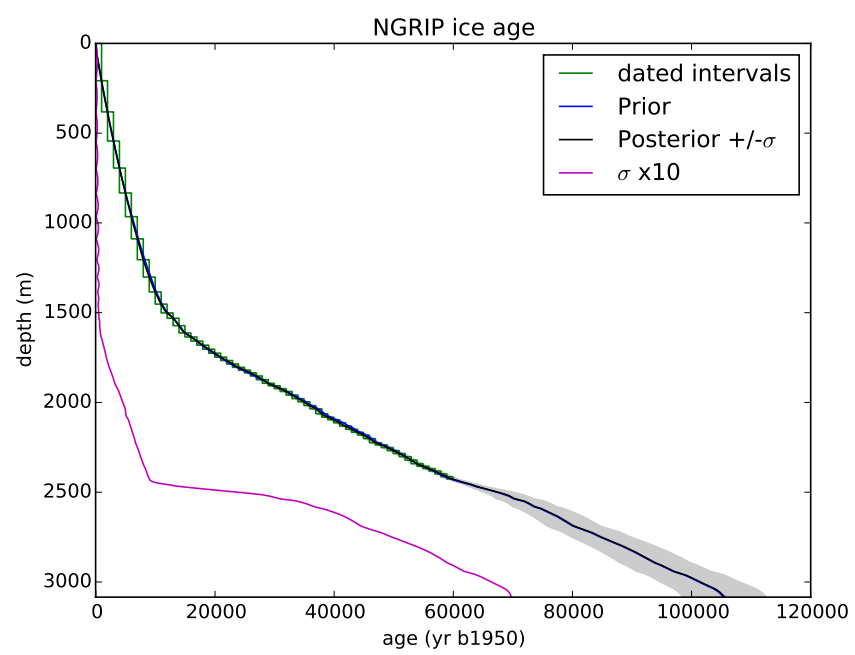

Figure 7. Experiment test-ice-intervals-with-known-durationswith-correlation. NGRIP prior (blue) and posterior (black) chronologies and the posterior confidence interval (grey area) when using correlated $1 \mathrm{kyr}$ long intervals with known durations from the GICC05 layer-counted timescale (green rectangles; Svensson et al., 2008). The $1 \sigma$ uncertainty of the posterior timescale is also shown on the left (pink). This figure is automatically produced by IceChrono1.

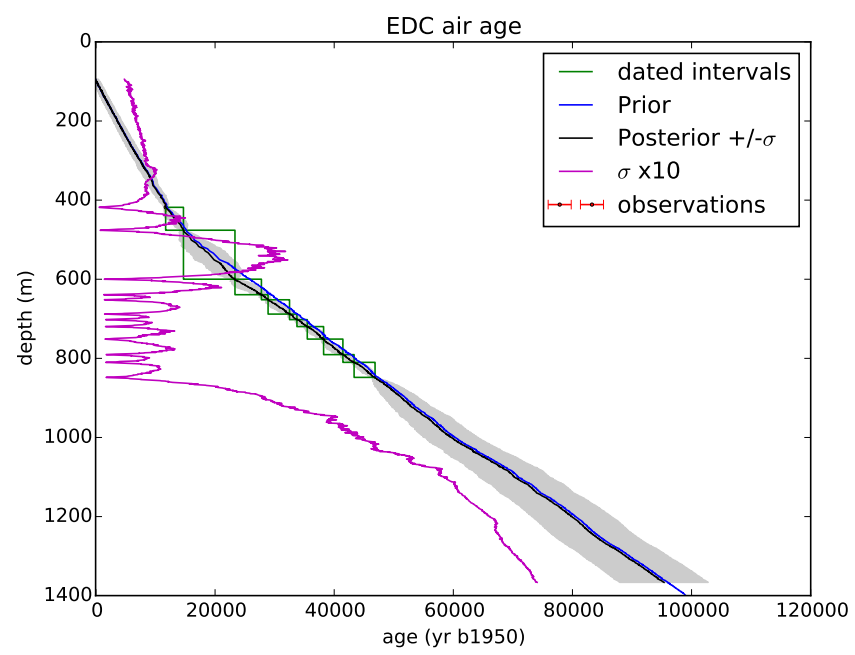

Figure 8. Experiment test-air-intervals-with-known-durations. EDC prior (blue) and posterior (black) chronologies and the posterior confidence interval (grey area) when using independent $\mathrm{CH} 4$ intervals with known durations from the GICC05 layer-counted timescale (green rectangles; Svensson et al., 2008). The $1 \sigma$ uncertainty of the posterior timescale is also shown on the left (pink). This figure is automatically produced by IceChrono1.

but it is numerically more stable since the LID is not fixed during the iterative optimization procedure.

The EDC air age results of IceChrono on this optimization experiment are plotted in Fig. 8. As expected, the timescale is well constrained by the GICC05 intervals with known du- rations of observations down to DO12 and explodes beyond this age. The uncertainty on the absolute age also tends to increase inside intervals with known durations. This is expected since the total duration of an interval is constrained, but inside this interval only the prior information constrains the variation of the age. This feature is more visible here than in the two previous experiments because of the uncertainty on the LID which has a direct impact on the uncertainty of the air age from Eq. (2). By comparison, the uncertainty of the accumulation rate only has an impact on the uncertainty of the derivative of the ice age from Eq. (1).

\subsection{Test experiment for mixed ice-air stratigraphic links}

We now perform a simplified dating experiment to test the inclusion of mixed ice-air stratigraphic links, which is a new type of observation in IceChrono1 with respect to the first version of Datice (Lemieux-Dudon et al., 2010a, b), not used in the AICC2012. This experiment is called test-mixed-strati. The experiment contains only the EDC and NGRIP ice cores. The resolution chosen for the correction functions is $200 \mathrm{yr}$ for the accumulation and LID correction functions and 501 nodes for the thinning correction function. We perform the dating experiment only down to a depth of $1400 \mathrm{~m}$ for the EDC ice core (age of $\sim 100 \mathrm{kyr}$ B1950).

The prior information for both the NGRIP and EDC ice cores are the same as for the test-ice-dated-intervals and test-air-dated-intervals experiments respectively. Only one type of observations is included: mixed ice-air stratigraphic links. This information comes from the synchronization of the EDC $\mathrm{CH}_{4}$ record with the NGRIP $\delta^{18} \mathrm{O}$ record. Each stratigraphic link is the onset of one DO event (including the Younger Dryas/Preboreal transition) down to DO12 ( $\sim 46.8 \mathrm{kyr}$ B1950). The EDC $\mathrm{CH}_{4}$ depths are taken from Loulergue et al. (2007, Table 2). The NGRIP $\delta^{18} \mathrm{O}$ depths are taken from Svensson et al. (2008, Table 1). The standard deviation of each observation is taken as $100 \mathrm{yr}$ for simplicity. The observations are assumed uncorrelated: the correlation matrix is assumed to be equal to the identity matrix.

The NGRIP air age vs. EDC ice age results of IceChrono1 on this optimization experiment are plotted in Fig. 9. While the prior scenario is in poor agreement with stratigraphic observations the optimized chronology agrees with the observations within their confidence intervals.

\section{Discussion}

\subsection{Robustness to a change of resolution}

It is important to assess whether the formulation of IceChrono1 is robust to a change of resolution: when the resolution increases, the simulations should converge toward a meaningful result. IceChrono1 uses two different types of 


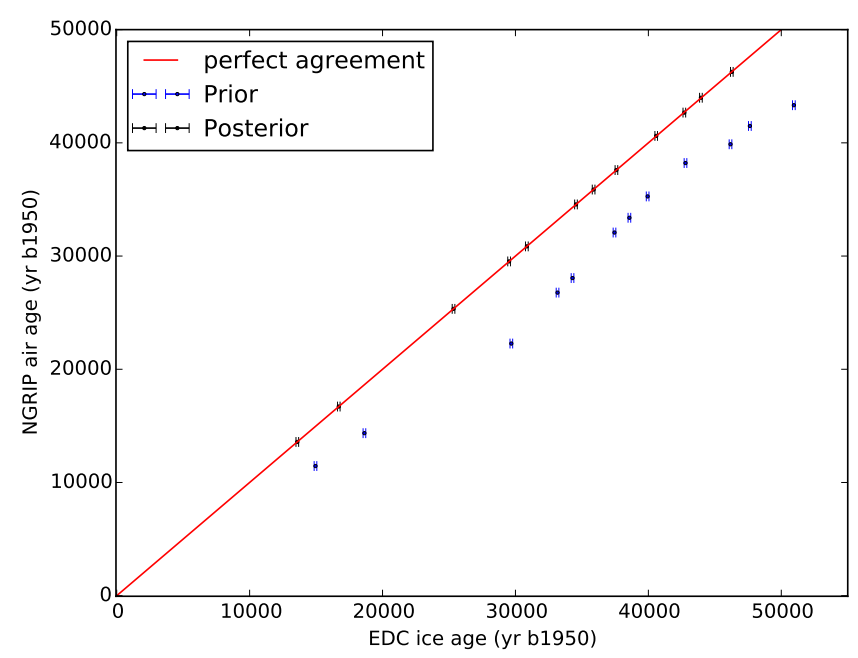

Figure 9. Experiment test-mixed-strati. NGRIP air age vs. EDC ice age for the prior (blue) and posterior (black) scenarios for the stratigraphic observations. The $1: 1$ perfect agreement line (red) is shown for comparison. This figure is automatically produced by IceChrono1.

grids to optimize the ice cores age scales: the age equation grids and the correction function grids.

The age equation grids are used to solve Eqs. (1), (2) and (3). Equation (2) is the value of the ice age function at a given depth, so it is clearly robust to a change of resolution. Equations (1) and (3) are integrals and are therefore also robust to a change of resolution.

Concerning the correction functions grids, we made two test experiments with different resolutions: AICC2012-VHR and AICC2012-V2HR. The fact that the AICC2012-VHR and AICC2012-V2HR experiments agree well indicates that the formulation of the optimization problem in IceChrono1 is robust to a change of resolution of the correction functions.

\subsection{IceChrono-Datice comparison on the AICC2012 experiment}

The fact that IceChrono1 and Datice agree fairly well on this AICC2012 experiment indicates that both codes, which have been developed independently using different programming languages and different numerical schemes, are correct. But one has to keep in mind that both codes are based on the same main principles, so this is not a confirmation of these principles.

Concerning the differences in the posterior confidence intervals observed for the last $60 \mathrm{kyr}$, we note that Datice uses an approximated version of Eq. (3) and that some limitations regarding the calculation of the uncertainties in Datice are known (see SOM, p. 280-289, of Bazin et al., 2014). These limitations are not present in IceChrono 1 and all the uncertainties are calculated using the same formula (Eq. 20). Some limitations have been corrected in a more recent version of Datice (Bazin et al., 2014). During the last glacial period, there are many $\mathrm{CH}_{4}$ Antarctica-NGRIP stratigraphic links with uncertainties of a few centuries. With the NGRIP chronology being tightly constrained to GICC05 within $50 \mathrm{yr}$, it is expected that the air age uncertainty at EDC will sometimes decrease below $1000 \mathrm{yr}$ during this time period. The posterior uncertainty calculated by IceChronol is therefore consistent with the chronological information used, in contradiction to that calculated by Datice.

\subsection{IceChrono new functionalities}

IceChrono1 has four new functionalities with respect to the initial Datice model (Lemieux-Dudon et al., 2010a, b):

- observations as ice intervals with known durations

- observations with correlated uncertainties

- observations as air intervals with known durations

- observations as mixed ice-air stratigraphic links.

We performed several tests which indicate that these functionalities work correctly. Note that the first two of these functionalities have also been implemented in a recent version of Datice (Bazin et al., 2014). The observations of intervals with known durations will be useful for future dating efforts to account for the layer counting information. This information is generally correlated since counting errors on two different intervals using the same method could be biased in the same way. Mixed ice-air stratigraphic observations will also be useful when accounting for the Antarctica$\mathrm{CH}_{4} /$ Greenland- $\delta^{18} \mathrm{O}$ synchronization links.

\subsection{IceChrono-Datice codes comparison}

Although IceChrono1 follows an approach similar to that of Datice, there are mathematical, numerical and programming differences with the initial version of Datice (LemieuxDudon et al., 2010a, b) that we will detail below.

1. Datice does not solve Eq. (3) but an approximation of it:

$$
\Delta d(z)=D^{\text {firn }}(z) \times l(z) \times \tau(z) ;
$$

that is, $\tau$ is assumed constant between the synchronous ice and air depths.

2. There is only one depth grid per drilling in Datice while the correction functions in IceChrono1 are discretized on different, coarser grids than the age equation grid. This allows reducing significantly the number of variables to be inverted and therefore to decrease the computation time. These coarser grids were not necessary in Datice since the analytical gradients already reduce the computation time. 
3. Uncertainties are assumed Gaussian on $\Delta$ depth observations in IceChrono1 while they are assumed lognormal in Datice. In practice, if the uncertainty on the $\Delta$ depth observation is small in front of the value of the $\Delta$ depth observation, this should make little difference.

4. In IceChrono1, we allow for mixed ice-air and air-ice stratigraphic links in between ice cores. This is new with respect to Datice. A concrete example of the use of mixed ice-air stratigraphic links could be the synchronization of Dansgaard-Oechger events recorded in the methane records in Antarctica and in the ice isotope records in Greenland, as illustrated in the testmixed-strati experiment. This is especially useful when methane records for some Greenland ice cores are not yet available at sufficient resolution.

5. IceChrono1 allows for ice and air intervals with known durations. The functionality of ice intervals with known durations has also recently been implemented in Datice (Bazin et al., 2014) to take into account the information from layer counting. An example of the use of air intervals with known durations could be the dating of one Antarctic ice core using its methane record synchronized to the NGRIP ice isotopic record dated by layer counting.

6. IceChrono1 allows for correlated errors in observations for every kind of observation, while the original version of Datice does not allow for correlated errors for observations (Bazin et al., 2013; Lemieux-Dudon et al., 2010a, b; Veres et al., 2013). Note however that a new version of Datice implements this new functionality (Bazin et al., 2014).

7. In IceChrono1, the Jacobians of the model and of the observation operator are computed numerically by a finite difference approach while they are computed analytically in Datice. The Jacobian of the observation operator is needed by the minimizer to find the optimal solution $X^{\text {opt }}$ and its uncertainty $\mathbf{C}^{X}$. When the optimal solution is found, the Jacobian of the model allows evaluating the uncertainty of the model $\mathbf{C}^{G}$ through Eq. (20). In Datice, analytical expressions of the Jacobians with respect to $\boldsymbol{X}$ have been derived and these expressions are used to numerically compute the Jacobians for a particular $\boldsymbol{X}$. In IceChrono, each component of the $\boldsymbol{X}$ vector is alternatively perturbed and the forward model is run to evaluate how the model $\boldsymbol{G}(\boldsymbol{X})$ and the observation operator are modified. In other words, the Jacobians are evaluated by a finite difference approach. While a numerical computation of the Jacobian leads to a slower computation time, it leads to a more flexible use of the model since, if one modifies the formulation of the cost function or of the model, one does not need to derive again analytical expressions for the Jacobians, which is a complex task.
8. IceChrono1 is coded in a simple, flexible and straightforward way using the object-oriented python language. It is very simple in IceChronol to modify the parameters of the problem, e.g., the age equation grid and the correction vectors grids. By comparison, IceChrono1 is about 1000 lines long (including the construction of the figures) while Datice is about 30000 lines long of fortran code (without any figure construction). The reduction of the code length in IceChrono is in particular due to (1) the use of the python programming language, which was not advanced enough at the time when the Datice code was developed; (2) the use of the python leastsq function, which automatically calculates the gradient of the observation operator and the posterior $\mathbf{C}^{X}$ variance-covariance matrix; and (3) the use of a numerical gradient of the model G'. Datice also implements posterior diagnostics of the data assimilation system which make its code length larger (Bazin et al., 2014). The simplicity of IceChrono will make it easy to add new functionalities to the code.

\subsection{Current limitations of IceChrono and possible perspectives}

IceChrono1 is already a useful tool to define a common and optimized chronology for several ice cores all together. However, it has several limitations that we will discuss below.

1. All uncertainties are assumed Gaussian. While the Gaussian probability density functions are the most often encountered in science, they are not always appropriate. For example, the volcanic synchronization of ice cores (e.g., Parrenin et al., 2012b) is ambiguous: a volcanic peak in one ice core can sometimes be synchronized to several other volcanic peaks in the other ice core. IceChrono1 therefore assumes that the features' recognition has been performed without ambiguity and that the only uncertainty remaining is the exact match of the two features within their durations.

2. The forward dating model is assumed to be "almost linear" in the plausible vicinity of the solution. Further developments would be necessary to diagnose if this assumption is justified.

3. IceChrono1 is not appropriate for optimizing the chronology of many ice cores at a very high resolution: the computation time would be too high, due to the numerical finite differences approach to evaluate the Jacobian matrices. In practice this is not a problem as a high resolution is only necessary for recent periods. If, in the future, the need for a more efficient dating model appears, we could develop an analytical gradient for the forward model, as it is done in the Datice software.

4. The age observations on different cores or on different ice core pairs are not always independent (because the 
dating methods are the same). We might allow in the future to take into account the correlation of observations between ice cores and ice core pairs.

5. IceChrono1 requires the need for external sedimentation models to infer prior scenarios and their uncertainties. In practice, these sedimentation models also need to be optimized using age observations. In a next step, we will incorporate sedimentation models directly into IceChrono. The uncertainties of these sedimentation models could be inferred automatically by comparing them to the age observations.

6. The stratigraphic observations between the different ice cores need to be derived externally and imported as stratigraphic observations into IceChrono1. This step also requires some prior knowledge about the sedimentation process. Therefore, it would be best to incorporate it directly into the IceChrono software. Automatic methods for ice core synchronization would eliminate this step, which is most of the time done visually, in a subjective, fastidious and undocumented way.

7. The layer counting dating of ice cores needs to be done externally and imported as intervals with known durations of observations into IceChrono1. Again, this step also requires prior knowledge about the sedimentation process (e.g., the typical annual layer thickness). Therefore, it would be best to incorporate it directly into the IceChrono software. An automatic method for layer counting has already been proposed (Winstrup et al., 2012).

8. The definition of realistic prior correlation matrices is a difficult issue which will be dealt with in details in future studies.

\section{Conclusions}

We have developed and made accessible a new open-source probabilistic model to produce a common and optimized age scale for several ice cores, taking into account modeling and observation information. The code is similar in scope to Datice but has mathematical, numerical and programming differences: IceChrono1 is simpler to use, more flexible to develop and more powerful than Datice, although it might be slower to run depending on the chosen resolution. When compared to an AICC2012-like experiment, IceChrono1 and Datice generally produce similar results, which is a confirmation of both codes but which is not a confirmation of their principles which are identical. There are some differences in the evaluation of AICC2012 uncertainties for the last glacial period, and IceChrono appears to be more consistent with the chronological information which have been used. We also tested four new features of IceChrono1 with respect to Datice: the use of ice intervals with known duration, the use of correlated observations, the use of air intervals with known durations, and the use mixed ice-air stratigraphic links. Although primarily built for ice cores, IceChronol can also be used to date other paleoclimatic archives like marine cores, lake cores, speleothems, etc.

The flexibility of IceChrono now opens interesting perspectives: the allowance of inter-cores and inter-core-pair correlation, the coupling with sedimentation models, the coupling with automatic synchronization methods, and the coupling with automatic layer counting methods. These developments will be made available in future versions of IceChrono. 


\section{Appendix A}

Below, we describe in detail the terms of the cost function which are linked to observations.

$j_{k}^{\mathrm{ih}}=\left(\boldsymbol{R}_{k}^{\mathrm{ih}}\right)^{\mathrm{T}}\left(\mathbf{P}_{k}^{\mathrm{ih}}\right)^{-1} \boldsymbol{R}_{k}^{\mathrm{ih}}$,

$\boldsymbol{R}_{k}^{\mathrm{ih}}=\left(\frac{\chi_{k}^{d}\left(z_{k, i}^{\mathrm{ih}}\right)-\chi_{k, i}^{\mathrm{obs}}}{\sigma_{k, i}^{\mathrm{ih}}}\right)_{i}$,

where $z_{k, i}^{\text {ih }}$ is the depth of the $i$ th ice-dated horizon in the $k$ th ice core, $\chi_{k, i}^{\mathrm{obs}}$ is its age, $\sigma_{k, i}^{\mathrm{ih}}$ is its standard deviation and where $\mathbf{P}_{k}^{\text {ih }}$ is the correlation matrix.

$j_{k}^{\mathrm{ah}}=\left(\boldsymbol{R}_{k}^{\mathrm{ah}}\right)^{\mathrm{T}}\left(\mathbf{P}_{k}^{\mathrm{ah}}\right)^{-1} \boldsymbol{R}_{k}^{\mathrm{ah}}$,

$\boldsymbol{R}_{k}^{\mathrm{ah}}=\left(\frac{\psi_{k}^{d}\left(z_{k, i}^{\mathrm{ah}}\right)-\psi_{k, i}^{\mathrm{obs}}}{\sigma_{k, i}^{\mathrm{ah}}}\right)_{i}$

where $z_{k, i}^{\text {ah }}$ is the depth of the $i$ th air-dated horizon in the $k^{\text {th }}$ ice core, $\psi_{k, i}^{\text {obs }}$ is its age, $\sigma_{k, i}^{\text {ah }}$ is its standard deviation and where $\mathbf{P}_{k}^{\text {ah }}$ is the correlation matrix.

$j_{k}^{\mathrm{ii}}=\left(\boldsymbol{R}_{k}^{\mathrm{ii}}\right)^{\mathrm{T}}\left(\mathbf{P}_{k}^{\mathrm{ii}}\right)^{-1} \boldsymbol{R}_{k}^{\mathrm{ii}}$,

$\boldsymbol{R}_{k}^{\mathrm{ii}}=\left(\frac{\chi_{k}^{d}\left(z_{k, i}^{\mathrm{ii}, \mathrm{b}}\right)-\chi_{k}^{d}\left(z_{k, i}^{\mathrm{ii}, \mathrm{t}}\right)-\Delta \chi_{k, i}^{\mathrm{obs}}}{\sigma_{k, i}^{\mathrm{ii}}}\right)_{i}$,

where $z_{k, i}^{\mathrm{iit}}$ and $z_{k, i}^{\mathrm{ii}, \mathrm{b}}$ are the top and bottom depths of the $i$ th ice-dated interval in the $k$ th ice core, $\Delta \chi_{k, i}^{\text {obs }}$ is its duration, $\sigma_{k, i}^{\mathrm{ii}}$ is its standard deviation and where $\mathbf{P}_{k}^{\mathrm{ii}}$ is the correlation matrix.

$j_{k}^{\mathrm{ai}}=\left(\boldsymbol{R}_{k}^{\mathrm{ai}}\right)^{\mathrm{T}}\left(\mathbf{P}_{k}^{\mathrm{ai}}\right)^{-1} \boldsymbol{R}_{k}^{\mathrm{ai}}$,

$\boldsymbol{R}_{k}^{\mathrm{ai}}=\left(\frac{\psi_{k}^{d}\left(z_{k, i}^{\mathrm{ai}, \mathrm{b}}\right)-\psi_{k}^{d}\left(z_{k, i}^{\mathrm{ai}, \mathrm{t}}\right)-\Delta \psi_{k, i}^{\mathrm{obs}}}{\sigma_{k, i}^{\mathrm{ai}}}\right)$,

where $z_{k, i}^{\mathrm{a}, \mathrm{t}}$ and $z_{k, i}^{\mathrm{ai}, \mathrm{b}}$ are the top and bottom depths of the $i$ th air-dated interval in the $k$ th ice core, $\Delta \psi_{k, i}^{\mathrm{obs}}$ is its duration, $\sigma_{k, i}^{\mathrm{ii}}$ is its standard deviation and where $\mathbf{P}_{k}^{\mathrm{ai}}$ is the correlation matrix.

$j_{k}^{\Delta d}=\left(\boldsymbol{R}_{k}^{\Delta d}\right)^{\mathrm{T}}\left(\mathbf{P}_{k}^{\Delta d}\right)^{-1} \boldsymbol{R}_{k}^{\Delta d}$,

$\boldsymbol{R}_{k}^{\Delta d}=\left(\frac{\Delta d_{k}^{d}\left(z_{k, i}^{\Delta d}\right)-\Delta d_{k, i}^{\mathrm{obs}}}{\sigma_{k, i}^{\Delta d}}\right)_{i}$,

where $z_{k, i}^{\Delta d}$ is the depth of the $i$ th $\Delta$ depth observation in the $k$ th ice core, $\Delta d_{k, i}^{\text {obs }}$ is its observed value, $\sigma_{k, i}^{\Delta d}$ is its standard deviation and where $\mathbf{P}_{k}^{\Delta d}$ is the correlation matrix.

$j_{k, m}^{\mathrm{ii}}=\left(\boldsymbol{R}_{k, m}^{\mathrm{ii}}\right)^{\mathrm{T}}\left(\mathbf{P}_{k, m}^{\mathrm{ii}}\right)^{-1} \boldsymbol{R}_{k, m}^{\mathrm{ii}}$,

$\boldsymbol{R}_{k, m}^{\mathrm{ii}}=\left(\frac{\chi_{k}^{d}\left(z_{k, m, i}^{\mathrm{ii}, 1}\right)-\chi_{m}^{d}\left(z_{k, m, i}^{\mathrm{ii}, 2}\right)}{\sigma_{k, m, i}^{\mathrm{ii}}}\right)_{i}$

where $z_{k, m, i}^{\mathrm{ii}, 1}$ and $z_{k, m, i}^{\mathrm{ii}, 2}$ are the depths in the $k$ th and $m$ th ice cores of the $i$ th ice-ice stratigraphic link in the $(k, m)$ pair of ice cores, $\sigma_{k, m, i}^{\mathrm{ii}}$ is its standard deviation and where $\mathbf{P}_{k, m}^{\mathrm{ii}}$ is the correlation matrix.

$j_{k, m}^{\mathrm{aa}}=\left(\boldsymbol{R}_{k, m}^{\mathrm{aa}}\right)^{\mathrm{T}}\left(\mathbf{P}_{k, m}^{\mathrm{aa}}\right)^{-1} \boldsymbol{R}_{k, m}^{\mathrm{aa}}$,

$\boldsymbol{R}_{k, m}^{\mathrm{aa}}=\left(\frac{\psi_{k}^{d}\left(z_{k, m, i}^{\mathrm{aa}, 1}\right)-\psi_{m}^{d}\left(z_{k, m, i}^{\mathrm{aa}, 2}\right)}{\sigma_{k, m, i}^{\mathrm{aa}}}\right)_{i}$,

where $z_{k, m, i}^{\mathrm{aa}, 1}$ and $z_{k, m, i}^{\mathrm{aa}, 2}$ are the depths in the $k$ th and $m$ th ice cores of the $i$ th air-air stratigraphic link in the $(k, m)$ pair of ice cores, $\sigma_{k, m, i}^{\mathrm{aa}}$ is its standard deviation and where $\mathbf{P}_{k, m}^{\mathrm{aa}}$ is the correlation matrix.

$$
\begin{aligned}
& j_{k, m}^{\mathrm{ia}}=\left(\boldsymbol{R}_{k, m}^{\mathrm{ia}}\right)^{\mathrm{T}}\left(\mathbf{P}_{k, m}^{\mathrm{ia}}\right)^{-1} \boldsymbol{R}_{k, m}^{\mathrm{ia}}, \\
& \boldsymbol{R}_{k, m}^{\mathrm{ia}}=\left(\frac{\chi_{k}^{d}\left(z_{k, m, i}^{\mathrm{ia}, 1}\right)-\psi_{m}^{d}\left(z_{k, m, i}^{\mathrm{ia}, 2}\right)}{\sigma_{k, m, i}^{\mathrm{ia}}}\right)_{i},
\end{aligned}
$$

where $z_{k, m, i}^{\mathrm{ia}, 1}$ and $z_{k, m, i}^{\mathrm{ia}, 2}$ are the depths in the $k$ th and $m$ th ice cores of the $i$ th ice-air stratigraphic link in the $(k, m)$ pair of ice cores, $\sigma_{k, m, i}^{\mathrm{ia}}$ is its standard deviation and where $\mathbf{P}_{k, m}^{\mathrm{ia}}$ is the correlation matrix.

$$
\begin{aligned}
& j_{k, m}^{\mathrm{ai}}=\left(\boldsymbol{R}_{k, m}^{\mathrm{ai}}\right)^{\mathrm{T}}\left(\mathbf{P}_{k, m}^{\mathrm{ai}}\right)^{-1} \boldsymbol{R}_{k, m}^{\mathrm{ai}}, \\
& \boldsymbol{R}_{k, m}^{\mathrm{ai}}=\left(\frac{\psi_{k}^{d}\left(z_{k, m, i}^{\mathrm{ai}, 1}\right)-\chi_{m}^{d}\left(z_{k, m, i}^{\mathrm{ai}, 2}\right)}{\sigma_{k, m, i}^{\mathrm{ai}}}\right)_{i},
\end{aligned}
$$

where $z_{k, m, i}^{\mathrm{ai}, 1}$ and $z_{k, m, i}^{\mathrm{ai}, 2}$ are the depths in the $k$ th and $m$ th ice cores of the $i$ th air-ice stratigraphic link in the $(k, m)$ pair of ice cores, $\sigma_{k, m, i}^{\text {ai }}$ is its standard deviation and where $\mathbf{P}_{k, m}^{\text {ai }}$ is the correlation matrix. 


\section{Appendix B: List of symbols}

\begin{tabular}{|c|c|}
\hline Symbol & Definition \\
\hline$k, m$ & Indices of ice cores \\
\hline$z_{k}$ & Depth \\
\hline$\chi_{k}$ & Ice age \\
\hline$D_{k}$ & Relative density \\
\hline$a_{k}$ & Accumulation rate \\
\hline$\tau_{k}^{n}$ & Thinning function \\
\hline$\Delta d_{k}$ & $\Delta$ depth, depth shift between synchronous ice and air events \\
\hline$l_{k}$ & Lock-in depth of air bubbles \\
\hline$D_{k}^{\text {firn }}$ & Average relative density between surface and lock-in depth \\
\hline$a_{k}^{\mathrm{b}}$ & Prior accumulation rate \\
\hline$l_{k}^{\mathrm{b}}$ & Prior lock-in depth of air bubbles \\
\hline$\tau_{k}^{\mathrm{b}}$ & Prior thinning function \\
\hline$c_{k}^{a}$ & Accumulation correction function \\
\hline$c_{k}^{\tilde{l}}$ & Lock-in depth correction function \\
\hline$c_{k}^{\tilde{\tau}}$ & Thinning correction function \\
\hline$z_{k, i}$ & Discretized depth $z_{k}$ for the solving the age equations \\
\hline$t_{k, i}^{a}$ & Discretized time for the accumulation correction function \\
\hline$t_{k, i}^{l}$ & Discretized time for the lock-in depth correction function \\
\hline$z_{k, i}^{\tau}$ & Discretized depth for the thinning correction function \\
\hline$C_{k}^{a}$ & Accumulation correction vector \\
\hline$C_{k}^{l}$ & Lock-in depth correction vector \\
\hline$C_{k}^{\kappa}$ & Thinning correction vector \\
\hline$X^{n}$ & State vector \\
\hline$L$ & Likelihood function \\
\hline$J$ & Cost function \\
\hline$J_{k}$ & Cost function term for ice core $k$ \\
\hline$J_{k, m}$ & Cost function term for ice core pair $(k, m)$ \\
\hline$J_{k}^{a}$ & Accumulation prior cost term \\
\hline$J_{k}^{l}$ & Lock-in depth prior cost term \\
\hline$J_{k}^{\tau}$ & Thinning prior cost term \\
\hline$J_{k}^{\mathrm{lih}}$ & Ice-dated horizons cost term \\
\hline$J_{k}^{\text {ah }}$ & Air-dated horizons cost term \\
\hline$J_{k}^{\mathrm{ii}}$ & Ice intervals with known durations cost term \\
\hline$J_{k}^{\mathrm{ai}}$ & Air intervals with known durations cost term \\
\hline$J_{k}^{\Delta d}$ & $\Delta$ depth cost term \\
\hline$J_{k, m}^{\mathrm{ii}}$ & Ice-ice stratigraphic links cost term \\
\hline$J_{k, m}^{\mathrm{aaa}}$ & Air-air stratigraphic links cost term \\
\hline$J_{k, m}^{\mathrm{ia}}$ & Ice-air stratigraphic links cost term \\
\hline$J_{k, m}^{\mathrm{ai}}$ & Air-ice stratigraphic links cost term \\
\hline $\mathbf{P}_{k}^{a}$ & Accumulation prior correlation matrix \\
\hline $\mathbf{P}_{k}^{l}$ & Lock-in depth prior correlation matrix \\
\hline $\mathbf{P}_{k}^{\tau}$ & Thinning prior correlation matrix \\
\hline $\boldsymbol{R}_{k}^{a}$ & Accumulation residual vector \\
\hline $\boldsymbol{R}_{k}^{\hat{l}}$ & Lock-in depth residual vector \\
\hline $\boldsymbol{R}_{k}^{\tau}$ & Thinning residual vector \\
\hline$\left(\sigma_{k, i}^{a}\right)_{i}$ & Accumulation prior standard deviation vector \\
\hline$\left(\sigma_{k, i}^{l}\right)_{i}$ & Lock-in depth prior standard deviation vector \\
\hline$\left(\sigma_{k, i}^{\tau}\right)_{i}$ & Thinning prior standard deviation vector \\
\hline$X^{\text {opt }}$ & Optimized model state vector \\
\hline $\mathbf{C}^{X}$ & A posteriori covariance matrix of the state vector \\
\hline $\mathbf{G}^{\prime}$ & Model Jacobian \\
\hline $\mathbf{C}^{G}$ & A posteriori covariance matrix of the model \\
\hline
\end{tabular}




\section{Code availability}

IceChrono1 is an open source model available under the General Public License v3. It is hosted on the github facility (https://github.com/parrenin/IceChrono). A mailing list exists for general support or discussions (https://groups. google.com/forum/?hl=_en\#!forum/icechrono). The current code (version 1.4) is also available as a Supplement to this manuscript.

\section{The Supplement related to this article is available online at doi:10.5194/gmd-8-1473-2015-supplement.}

Acknowledgements. This work benefited from helpful comments by E. Wolff, T. Heaton, and two other anonymous reviewers. We also thank Florent Molliex, Delphine Tardif-Becquet, M. Sacchettini, M. Nodet and E. Blayo for helpful exchanges. This work was funded by the INSU/LEFE project IceChrono and by the ANR project ADAGe.

Edited by: D. Goldberg

\section{References}

Aciego, S., Bourdon, B., Schwander, J., Baur, H., and Forieri, A.: Toward a radiometric ice clock: uranium ages of the Dome $\mathrm{C}$ ice core, Quaternary Sci. Rev., 30, 2389-2397, 2011.

Ahn, J. and Brook, E. J.: Siple Dome ice reveals two modes of millennial $\mathrm{CO}_{2}$ change during the last ice age, Nat. Commun., 5, 3723, doi:10.1038/ncomms4723, 2014.

Bard, E., Raisbeck, G. M., Yiou, F., and Jouzel, J.: Solar modulation of cosmogenic nuclide production over the last millennium: comparison between ${ }^{14} \mathrm{C}$ and ${ }^{10} \mathrm{Be}$ records, Earth Planet. Sci. Lett., 150, 453-462, 1997.

Barker, S., Knorr, G., Edwards, R. L., Parrenin, F., Putnam, A. E., Skinner, L. C., Wolff, E., and Ziegler, M.: 800,000 Years of Abrupt Climate Variability, Science, 334, 347-351, doi:10.1126/science.1203580, 2011.

Bazin, L., Landais, A., Lemieux-Dudon, B., Toyé Mahamadou Kele, H., Veres, D., Parrenin, F., Martinerie, P., Ritz, C., Capron, E., Lipenkov, V., Loutre, M.-F., Raynaud, D., Vinther, B., Svensson, A., Rasmussen, S. O., Severi, M., Blunier, T., Leuenberger, M., Fischer, H., Masson-Delmotte, V., Chappellaz, J., and Wolff, E.: An optimized multi-proxy, multi-site Antarctic ice and gas orbital chronology (AICC2012): 120-800 ka, Clim. Past, 9, 17151731, doi:10.5194/cp-9-1715-2013, 2013.

Bazin, L., Lemieux-Dudon, B., Landais, A., Guillevic, M., Kindler, P., Parrenin, F., and Martinerie, P.: Optimisation of glaciological parameters for ice core chronology by implementing counted layers between identified depth levels, Clim. Past Discuss., 10, 3585-3616, doi:10.5194/cpd-10-3585-2014, 2014.

Bender, M., Sowers, T., Dickson, M. L., Orchado, J., Grootes, P., Mayewski, P. A.. and Meese, D. A.: Climate connection between Greenland and Antarctica during the last 100,000 years, Nature, 372, 663-666, 1994.
Bender, M. L.: Orbital tuning chronology for the Vostok climate record supported by trapped gas composition, Earth Planet. Sci. Lett., 204, 275-289, 2002.

Blunier, T. and Brook, E. J.: Timing of millennial-scale climate change in Antarctica and Greenland during the last glacial period, Science, 291, 109-112, 2001.

Buiron, D., Chappellaz, J., Stenni, B., Frezzotti, M., Baumgartner, M., Capron, E., Landais, A., Lemieux-Dudon, B., MassonDelmotte, V., Montagnat, M., Parrenin, F., and Schilt, A.: TALDICE-1 age scale of the Talos Dome deep ice core, East Antarctica, Clim. Past, 7, 1-16, doi:10.5194/cp-7-1-2011, 2011.

Buizert, C., Baggenstos, D., Jiang, W., Purtschert, R., Petrenko, V. V., Lu, Z.-T., Müller, P., Kuhl, T., Lee, J., Severinghaus, J. P., and Brook, E. J.: Radiometric ${ }^{81} \mathrm{Kr}$ dating identifies 120,000 -yearold ice at Taylor Glacier, Antarctica, Proc. Natl. Acad. Sci., 111, 6876-6881, 2014.

Buizert, C., Cuffey, K. M., Severinghaus, J. P., Baggenstos, D., Fudge, T. J., Steig, E. J., Markle, B. R., Winstrup, M., Rhodes, R. H., Brook, E. J., Sowers, T. A., Clow, G. D., Cheng, H., Edwards, R. L., Sigl, M., McConnell, J. R., and Taylor, K. C.: The WAIS Divide deep ice core WD2014 chronology - Part 1: Methane synchronization (68-31 ka BP) and the gas age-ice age difference, Clim. Past, 11, 153-173, doi:10.5194/cp-11-153-2015, 2015.

Caillon, N., Severinghaus, J. P., Jouzel, J., Barnola, J.-M., Kang, J., and Lipenkov, V. Y.: Timing of Atmospheric $\mathrm{CO}_{2}$ and Antarctic Temperature Changes Across Termination III, Science, 299, 1728-1731, doi:10.1126/science.1078758, 2003.

Capron, E., Landais, A., Lemieux-Dudon, B., Schilt, A., MassonDelmotte, V., Buiron, D., Chappellaz, J., Dahl-Jensen, D., Johnsen, S., Leuenberger, M., Loulergue, L., and Oerter, H.: Synchronising EDML and NorthGRIP ice cores using $\delta^{18} \mathrm{O}$ of atmospheric oxygen $\left(\delta^{18} \mathrm{O}_{\mathrm{atm}}\right)$ and $\mathrm{CH}_{4}$ measurements over MIS5 (80-123 kyr), Quaternary Sci. Rev., 29, 222-234, doi:10.1016/j.quascirev.2009.07.014, 2010.

Capron, E., Landais, A., Buiron, D., Cauquoin, A., Chappellaz, J., Debret, M., Jouzel, J., Leuenberger, M., Martinerie, P., MassonDelmotte, V., Mulvaney, R., Parrenin, F., and Prié, F.: Glacialinterglacial dynamics of Antarctic firn columns: comparison between simulations and ice core air- $\delta^{15} \mathrm{~N}$ measurements, Clim. Past, 9, 983-999, doi:10.5194/cp-9-983-2013, 2013.

Dreyfus, G. B., Parrenin, F., Lemieux-Dudon, B., Durand, G., Masson-Delmotte, V., Jouzel, J., Barnola, J.-M., Panno, L., Spahni, R., Tisserand, A., Siegenthaler, U., and Leuenberger, M.: Anomalous flow below $2700 \mathrm{~m}$ in the EPICA Dome C ice core detected using $\delta^{18} \mathrm{O}$ of atmospheric oxygen measurements, Clim. Past, 3, 341-353, doi:10.5194/cp-3-341-2007, 2007.

Dreyfus, G. B., Raisbeck, G. M., Parrenin, F., Jouzel, J., Guyodo, Y., Nomade, S., and Mazaud, A.: An ice core perspective on the age of the Matuyama-Brunhes boundary, Earth Planet. Sci. Lett., 274, 151-156, doi:10.1016/j.eps1.2008.07.008, 2008.

Dunbar, N. W., McIntosh, W. C., and Esser, R. P.: Physical setting and tephrochronology of the summit caldera ice record at Mount Moulton, West Antarctica, Geol. Soc. Am. Bull., 120, 796-812, 2008.

EPICA community members: 8 glacial cycles from an Antarctic ice core, Nature, 429, 623-628, 2004.

EPICA community members: One-to-one coupling of glacial climate variability in Greenland and Antarctica, Nature, 444, 195198, 2006. 
Goujon, C., Barnola, J.-M., and Ritz, C.: Modeling the densification of polar firn including heat diffusion: application to closeoff characteristics and gas isotopic fractionation for Antarctica and Greenland sites, J. Geophys. Res., 108, ACL10/1-10, doi:10.1029/2002JD003319, 2003.

Huber, C., Leuenberger, M., Spahni, R., Flückiger, J., Schwander, J., Stocker, T. F., Johnsen, S., Landais, A., and Jouzel, J.: Isotope calibrated Greenland temperature record over Marine Isotope Stage 3 and its relation to $\mathrm{CH}_{4}$, Earth Planet. Sci. Lett., 243(3-4), 504-519, doi:10.1016/j.eps1.2006.01.002, 2006.

Huybrechts, P., Rybak, O., Pattyn, F., Ruth, U., and Steinhage, D.: Ice thinning, upstream advection, and non-climatic biases for the upper $89 \%$ of the EDML ice core from a nested model of the Antarctic ice sheet, Clim. Past, 3, 577-589, doi:10.5194/cp-3577-2007, 2007.

Johnsen, S. J., Dahl-Jensen, D., Gundestrup, N., Steffensen, J. P., Clausen, H. B., Miller, H., Masson-Delmotte, V., Sveinbjornsdottir, A. E., and White, J.: Oxygen isotope and palaeotemperature records from six Greenland ice-core stations: Camp Century, Dye-3, GRIP, GISP2, Renland and NorthGRIP, J. Quaternary Sci., 16, 299-307, 2001.

Jouzel, J., Masson-Delmotte, V., Cattani, O., Dreyfus, G., Falourd, S., Hoffmann, G., Minster, B., Nouet, J., Barnola, J. M., Chappellaz, J., Fischer, H., Gallet, J. C., Johnsen, S., Leuenberger, M., Loulergue, L., Luethi, D., Oerter, H., Parrenin, F., Raisbeck, G., Raynaud, D., Schilt, A., Schwander, J., Selmo, E., Souchez, R., Spahni, R., Stauffer, B., Steffensen, J. P., Stenni, B., Stocker, T. F., Tison, J. L., Werner, M., and Wolff, E. W.: Orbital and Millennial Antarctic Climate Variability over the Past 800,000 Years, Science, 317, 793-796, doi:10.1126/science.1141038, 2007.

Kawamura, K., Parrenin, F., Uemura, R., Vimeux, F., Severinghaus, J. P., Matsumoto, K., Nakata, H., Nakazawa, T., Aoki, S., Jouzel, J., Fujii, Y., and Watanabe, O.: Northern Hemisphere forcing of climatic cycles over the past 360,000 years implied by absolute dating of Antarctic ice cores, Nature, 448, 912-917, doi:10.1038/nature06015, 2007.

Lambert, F., Bigler, M., Steffensen, J. P., Hutterli, M., and Fischer, H.: Centennial mineral dust variability in high-resolution ice core data from Dome C, Antarctica, Clim. Past, 8, 609-623, doi:10.5194/cp-8-609-2012, 2012.

Landais, A., Barnola, J. M., Masson-Delmotte, V., Jouzel, J., Chappellaz, J., Caillon, N., Huber, C., Leuenberger, M., and Johnsen, S. J.: A continuous record of temperature evolution over a sequence of Dansgaard-Oeschger events during Marine Isotopic Stage 4 (76 to $62 \mathrm{kyr}$ BP), Geophys. Res. Lett., 31, L22211, doi:10.1029/2004GL021193, 2004.

Landais, A., Jouzel, J., Masson-Delmotte, V., and Caillon, N.: Large temperature variations over rapid climatic events in Greenland: a method based on air isotopic measurements, Comptes Rendus Geosci., 337, 947-956, 2005.

Landais, A., Waelbroeck, C., and Masson-Delmotte, V.: On the limits of Antarctic and marine climate records synchronization: Lag estimates during marine isotopic stages $5 \mathrm{~d}$ and $5 \mathrm{c}$, Paleoceanography, 21, PA1001, doi:10.1029/2005PA001171, 2006.

Landais, A., Dreyfus, G., Capron, E., Pol, K., Loutre, M. F., Raynaud, D., Lipenkov, V. Y., Arnaud, L., Masson-Delmotte, V., Paillard, D., Jouzel, J., and Leuenberger, M.: Towards orbital dating of the EPICA Dome $\mathrm{C}$ ice core using $\delta \mathrm{O}_{2} / \mathrm{N}_{2}$, Clim. Past, 8 , 191-203, doi:10.5194/cp-8-191-2012, 2012.
Landais, A., Dreyfus, G., Capron, E., Jouzel, J., Masson-Delmotte, V., Roche, D. M., Prié, F., Caillon, N., Chappellaz, J., Leuenberger, M., Lourantou, A., Parrenin, F., Raynaud, D., and Teste, G.: Two-phase change in $\mathrm{CO} 2$, Antarctic temperature and global climate during Termination II, Nat. Geosci., 6, 1062-1065, doi:10.1038/ngeo1985, 2013.

Lemieux-Dudon, B., Blayo, Petit, J. R. E., Waelbroeck, C., Svensson, A., Ritz, C., Barnola, J.-M., Narcisi, B. M., and Parrenin, F. Consistent dating for Antarctica and Greenland ice cores, Quaternary Sci. Rev., 29, 8-20, 2010a.

Lemieux-Dudon, B., Parrenin, F., and Blayo, E.: A Probabilistic Method to Construct an Optimal Ice Chronology for Ice Cores, in: Physics of Ice Core Records 2, edited by: Hondoh, T., $2010 \mathrm{~b}$.

Levenberg, K.: A method for the solution of certain problems in least squares, Q. Appl. Math., 2, 164-168, 1944.

Lipenkov, V. Y., Raynaud, D., Loutre, M. F., and Duval, P.: On the potential of coupling air content and $\mathrm{O}_{2} / \mathrm{N}_{2}$ from trapped air for establishing an ice core chronology tuned on local insolation, Quaternary Sci. Rev., 30, 3280-3289, 2011.

Lliboutry, L.: A critical review of analytical approximate solutions for steady state velocities and temperature in cold ice sheets, $\mathrm{Z}$. Gletscher. Glacialgeol., 15, 135-148, 1979.

Loulergue, L., Parrenin, F., Blunier, T., Barnola, J.-M., Spahni, R., Schilt, A., Raisbeck, G., and Chappellaz, J.: New constraints on the gas age-ice age difference along the EPICA ice cores, 0-50 kyr, Clim. Past, 3, 527-540, doi:10.5194/cp-3-527-2007, 2007.

Loulergue, L., Schilt, A., Spahni, R., Masson-Delmotte, V., Blunier, T., Lemieux, B., Barnola, J. M., Raynaud, D., Stocker, T. F., and Chappellaz, J.: Orbital and millennial-scale features of atmospheric $\mathrm{CH}_{4}$ over the past 800,000 years, Nature, 453, 383-386, 2008.

Marcott, S. A., Bauska, T. K., Buizert, C., Steig, E. J., Rosen, J. L., Cuffey, K. M., Fudge, T. J., Severinghaus, J. P., Ahn, J., Kalk, M. L., McConnell, J. R., Sowers, T., Taylor, K. C., White, J. W. C., and Brook, E. J.: Centennial-scale changes in the global carbon cycle during the last deglaciation, Nature, 514, 616-619, 2014.

Marquardt, D. W.: An algorithm for least-squares estimation of nonlinear parameters, J. Soc. Ind. Appl. Math., 11, 431-441, 1963.

Monnin, E., Indermühle, A., Dällenbach, A., Flückiger, J., Stauffer, B., Stocker, T. F., Raynaud, D., and Barnola, J.-M.: Atmospheric $\mathrm{CO}_{2}$ concentrations over the last glacial termination, Science, 291, 112-114, 2001.

Monnin, E., Steig, E. J., Siegenthaler, U., Kawamura, K., Schwander, J., Stauffer, B., Stocker, T. F., Morse, D. L., Barnola, J.M., Bellier, B., Raynaud, D., and Fischer, H.: Evidence for substantial accumulation rate variability in Antarctica during the Holocene, through synchronization of $\mathrm{CO}_{2}$ in the Taylor Dome, Dome C and DML ice cores, Earth Planet. Sci. Lett., 224, 45-54, 2004.

Narcisi, B., Petit, J.-R., and Tiepolo, M.: A volcanic marker (92 ka) for dating deep east Antarctic ice cores, Quaternary Sci. Rev., 25, 2682-2687, 2006.

NEEM community Members: Eemian interglacial reconstructed from a Greenland folded ice core, Nature, 493, 489-494, doi:10.1038/nature11789, 2013.

NorthGRIP project members: High-resolution record of Northern Hemisphere climate extending into the last interglacial period, Nature, 431, 147-151, 2004. 
PAGES 2k consortium: Continental-scale temperature variability during the past two millennia, Nat. Geosci., 6, 339-346, 2013.

Parrenin, F. and Hindmarsh, R. C. A.: Influence of a non-uniform velocity field on isochrone geometry along a steady flowline of an ice sheet, J. Glaciol., 53, 612-622, 2007.

Parrenin, F., Jouzel, J., Waelbroeck, C., Ritz, C., and Barnola, J.-M.: Dating the Vostok ice core by an inverse method, J. Geophys. Res., 106, 31831-837851, 2001.

Parrenin, F., Rémy, F., Ritz, C., Siegert, M., and Jouzel, J.: New modelling of the Vostok ice flow line and implication for the glaciological chronology of the Vostok ice core, J. Geophys. Res., 109, D20102, doi:10.1029/2004JD004561, 2004.

Parrenin, F., Hindmarsh, R. C. H., and Rémy, F.: Analytical solutions for the effect of topography, accumulation rate and lateral flow divergence on isochrone layer geometry, J. Glaciol., 52, 191-202, 2006.

Parrenin, F., Barnola, J.-M., Beer, J., Blunier, T., Castellano, E., Chappellaz, J., Dreyfus, G., Fischer, H., Fujita, S., Jouzel, J., Kawamura, K., Lemieux-Dudon, B., Loulergue, L., MassonDelmotte, V., Narcisi, B., Petit, J.-R., Raisbeck, G., Raynaud, D., Ruth, U., Schwander, J., Severi, M., Spahni, R., Steffensen, J. P., Svensson, A., Udisti, R., Waelbroeck, C., and Wolff, E.: The EDC3 chronology for the EPICA Dome C ice core, Clim. Past, 3, 485-497, doi:10.5194/cp-3-485-2007, 2007a.

Parrenin, F., Dreyfus, G., Durand, G., Fujita, S., Gagliardini, O., Gillet, F., Jouzel, J., Kawamura, K., Lhomme, N., MassonDelmotte, V., Ritz, C., Schwander, J., Shoji, H., Uemura, R., Watanabe, O., and Yoshida, N.: 1-D-ice flow modelling at EPICA Dome C and Dome Fuji, East Antarctica, Clim. Past, 3, 243-259, doi:10.5194/cp-3-243-2007, 2007b.

Parrenin, F., Barker, S., Blunier, T., Chappellaz, J., Jouzel, J., Landais, A., Masson-Delmotte, V., Schwander, J., and Veres, D.: On the gas-ice depth difference ( $\Delta$ depth) along the EPICA Dome C ice core, Clim. Past, 8, 1239-1255, doi:10.5194/cp-8-12392012, 2012a.

Parrenin, F., Petit, J.-R., Masson-Delmotte, V., Wolff, E., BasileDoelsch, I., Jouzel, J., Lipenkov, V., Rasmussen, S. O., Schwander, J., Severi, M., Udisti, R., Veres, D., and Vinther, B. M.: Volcanic synchronisation between the EPICA Dome $\mathrm{C}$ and Vostok ice cores (Antarctica) 0-145 kyr BP, Clim. Past, 8, 1031-1045, doi:10.5194/cp-8-1031-2012, 2012b.

Parrenin, F., Masson-Delmotte, V., Köhler, P., Raynaud, D., Paillard, D., Schwander, J., Barbante, C., Landais, A., Wegner, A., and Jouzel, J.: Synchronous change of atmospheric $\mathrm{CO}_{2}$ and Antarctic temperature during the last deglacial warming, Science, 339, 1060-1063, 2013.

Pedro, J. B., van Ommen, T. D., Rasmussen, S. O., Morgan, V. I., Chappellaz, J., Moy, A. D., Masson-Delmotte, V., and Delmotte, M.: The last deglaciation: timing the bipolar seesaw, Clim. Past, 7, 671-683, doi:10.5194/cp-7-671-2011, 2011.

Petit, J. R., Jouzel, J., Raynaud, D., Barkov, N. I., Barnola, J.-M., Basile, I., Bender, M., Chappellaz, J., Devis, M., Delaygue, G., Delmotte, M., Kotlyakov, V. M., Legrand, M., Lipenkov, V. Y., Lorius, C., Pepin, L., Ritz, C., Saltzman, E., and Stievenard, M.: Climate and atmospheric history of the past 420,000 years from the Vostok ice core, Antarctica, Nature, 399, 429-436, 1999.

Raisbeck, G. M., Yiou, F., Bard, E., Dollfus, D., Jouzel, J., and Petit, J. R.: Absolute dating of the last 7000 years of the Vostok ice core using ${ }^{10}$ Be, Miner. Mag, 62A, p. 1228, 1998.
Raisbeck, G. M., Yiou, F., Cattani, O., and Jouzel, J.: 10Be evidence for the Matuyama-Brunhes geomagnetic reversal in the EPICA Dome C ice core, Nature, 444, 82-84, 2006.

Raisbeck, G. M., Yiou, F., Jouzel, J., and Stocker, T. F.: Direct north-south synchronization of abrupt climate change record in ice cores using Beryllium 10, Clim. Past, 3, 541-547, doi:10.5194/cp-3-541-2007, 2007.

Rasmussen, S. O., Andersen, K. K., Svensson, A. M., Steffensen, J. P., Vinther, B. M., Clausen, H. B., Siggaard-Andersen, M.L., Johnsen, S. J., Larsen, L. B., Dahl-Jensen, D., Bigler, M., Rothlisberger, R., Fischer, H., Goto-Azuma, K., Hansson, M. E., and Ruth, U.: A new Greenland ice core chronology for the last glacial termination, J. Geophys. Res., 111, D06102, doi:10.1029/2005JD006079, 2006.

Raynaud, D., Lipenkov, V., Lemieux-Dudon, B., Duval, P., Loutre, M.-F., and Lhomme, N.: The local insolation signature of air content in Antarctic ice. A new step toward an absolute dating of ice records, Earth Planet. Sci. Lett., 261, 337-349, 2007.

Röthlisberger, R., Mudelsee, M., Bigler, M., de Angelis, M., Fischer, H., Hansson, M., Lambert, F., Masson-Delmotte, V., Sime, L., Udisti, R., and Wolff, E. W.: The Southern Hemisphere at glacial terminations: insights from the Dome $\mathrm{C}$ ice core, Clim. Past, 4, 345-356, doi:10.5194/cp-4-345-2008, 2008.

Schilt, A., Baumgartner, M., Blunier, T., Schwander, J., Spahni, R., Fischer, H., and Stocker, T. F.: Glacial-interglacial and millennial-scale variations in the atmospheric nitrous oxide concentration during the last 800,000 years, Quaternary Sci. Rev., 29, 182-192, 2010.

Schoenemann, S. W., Steig, E. J., Ding, Q., Markle, B. R., and Schauer, A. J.: Triple water-isotopologue record from WAIS Divide, Antarctica: Controls on glacial-interglacial changes in ${ }^{17} \mathrm{O}_{\text {excess }}$ of precipitation, J. Geophys. Res.-Atmos., 119, 87418763, 2014.

Schüpbach, S., Federer, U., Bigler, M., Fischer, H., and Stocker, T. F.: A refined TALDICE-1a age scale from 55 to $112 \mathrm{ka}$ before present for the Talos Dome ice core based on highresolution methane measurements, Clim. Past, 7, 1001-1009, doi:10.5194/cp-7-1001-2011, 2011.

Schwander, J., Barnola, J.-M., Andrié, C., Leuenberger, M., Ludin, A., Raynaud, D., and Stauffer, B.: The age of the air in the firn and the ice at Summit, Greenland, J. Geophys. Res.-Atmos., 98, 2831-2838, 1993.

Seierstad, I. K., Abbott, P. M., Bigler, M., Blunier, T., Bourne, A. J., Brook, E., Buchardt, S. L., Buizert, C., Clausen, H. B., Cook, E., Dahl-Jensen, D., Davies, S. M., Guillevic, M., Johnsen, S. J., Pedersen, D. S., Popp, T. J., Rasmussen, S. O., Severinghaus, J. P., Svensson, A., and Vinther, B. M.: Consistently dated records from the Greenland GRIP, GISP2 and NGRIP ice cores for the past $104 \mathrm{ka}$ reveal regional millennial-scale $\delta^{18} \mathrm{O}$ gradients with possible Heinrich event imprint, Quaternary Sci. Rev., 106, 2946, 2014.

Severi, M., Becagli, S., Castellano, E., Morganti, A., Traversi, R., Udisti, R., Ruth, U., Fischer, H., Huybrechts, P., Wolff, E., Parrenin, F., Kaufmann, P., Lambert, F., and Steffensen, J. P.: Synchronisation of the EDML and EDC ice cores for the last 52 kyr by volcanic signature matching, Clim. Past, 3, 36700374, doi:10.5194/cp-3-367-2007, 2007.

Severi, M., Udisti, R., Becagli, S., Stenni, B., and Traversi, R.: Volcanic synchronisation of the EPICA-DC and TALDICE ice cores 
for the last $42 \mathrm{kyr}$ BP, Clim. Past, 8, 509-517, doi:10.5194/cp-8509-2012, 2012.

Sigl, M., McConnell, J. R., Toohey, M., Curran, M., Das, S. B., Edwards, R., Isaksson, E., Kawamura, K., Kipfstuhl, S., Krüger, K., Layman, L., Maselli, O. J., Motizuki, Y., Motoyama, H., Pasteris, D. R., and Severi, M.: Insights from Antarctica on volcanic forcing during the Common Era, Nat. Clim. Change, 4, 693-697, 2014.

Singer, B. S., Guillou, H., Jicha, B. R., Laj, C., Kissel, C., Beard, B. L., and Johnson, C. M.: ${ }^{40} \mathrm{Ar} /{ }^{39} \mathrm{Ar}, \mathrm{K}-\mathrm{Ar}$ and ${ }^{230} \mathrm{Th}-{ }^{238} \mathrm{U}$ dating of the Laschamp excursion: a radioisotopic tie-point for ice core and climate chronologies, Earth Planet. Sci. Lett., 286, 80-88, 2009.

Stenni, B., Masson-Delmotte, V., Selmo, E., Oerter, H., Meyer, H., Röthlisberger, R., Jouzel, J., Cattani, O., Falourd, S., Fischer, H., Hoffmann, G., Iacumin, P., Johnsen, S. J., Minster, B., and Udisti, R.: The deuterium excess records of EPICA Dome C and Dronning Maud Land ice cores (East Antarctica), Quaternary Sci. Rev., 29, 146-159, doi:10.1016/j.quascirev.2009.10.009, 2010.

Suwa, M. and Bender, M. L.: Chronology of the Vostok ice core constrained by $\mathrm{O}_{2} / \mathrm{N}_{2}$ ratios of occluded air, and its implication for the Vostok climate records, Quaternary Sci. Rev., 27, 1093 1106, 2008.

Svensson, A., Andersen, K. K., Bigler, M., Clausen, H. B., DahlJensen, D., Davies, S. M., Johnsen, S. J., Muscheler, R., Parrenin, F., Rasmussen, S. O., Röthlisberger, R., Seierstad, I., Steffensen, J. P., and Vinther, B. M.: A 60000 year Greenland stratigraphic ice core chronology, Clim. Past, 4, 47-57, doi:10.5194/cp-4-472008, 2008.

Svensson, A., Bigler, M., Blunier, T., Clausen, H. B., Dahl-Jensen, D., Fischer, H., Fujita, S., Goto-Azuma, K., Johnsen, S. J., Kawamura, K., Kipfstuhl, S., Kohno, M., Parrenin, F., Popp, T., Rasmussen, S. O., Schwander, J., Seierstad, I., Severi, M., Steffensen, J. P., Udisti, R., Uemura, R., Vallelonga, P., Vinther, B. M., Wegner, A., Wilhelms, F., and Winstrup, M.: Direct linking of Greenland and Antarctic ice cores at the Toba eruption (74 ka BP), Clim. Past, 9, 749-766, doi:10.5194/cp-9-749-2013, 2013.

Tarantola, A.: Inverse problem theory and methods for model parameter estimation, Society for Industrial Mathematics, 2005.

Udisti, R., Becagli, S., Castellano, E., Delmonte, B., Jouzel, J., Petit, J.-R., Schwander, J., Stenni, B., and Wolff, E. W.: Stratigraphic correlations between the EPICA-Dome C and Vostok ice cores showing the relative variations of snow accumulation over the past $45 \mathrm{kyr}$, J. Geophys. Res., 109, D08101, doi:10.1029/2003JD004180, 2004.
Veres, D., Bazin, L., Landais, A., Toyé Mahamadou Kele, H., Lemieux-Dudon, B., Parrenin, F., Martinerie, P., Blayo, E., Blunier, T., Capron, E., Chappellaz, J., Rasmussen, S. O., Severi, M., Svensson, A., Vinther, B., and Wolff, E. W.: The Antarctic ice core chronology (AICC2012): an optimized multi-parameter and multi-site dating approach for the last 120 thousand years, Clim. Past, 9, 1733-1748, doi:10.5194/cp-9-1733-2013, 2013.

Vinther, B., Clausen, H., Kipfstuhl, S., Fischer, H., Bigler, M., Oerter, H., Wegner, A., Wilhelms, F., Sevri, M., Udisti, R. and others: A stratigraphic Antarctic chronology covering the past 16700 years in the EPICA deep ice core from Dronning Maud Land, in preparation, 2013.

WAIS Divide Project Members: Onset of deglacial warming in West Antarctica driven by local orbital forcing, Nature, 500, 440-444, 2013.

Winkler, R., Landais, A., Sodemann, H., Dümbgen, L., Prié, F., Masson-Delmotte, V., Stenni, B., and Jouzel, J.: Deglaciation records of ${ }^{17} \mathrm{O}$-excess in East Antarctica: reliable reconstruction of oceanic normalized relative humidity from coastal sites, Clim. Past, 8, 1-6, doi:10.5194/cp-8-1-2012, 2012.

Winstrup, M., Svensson, A. M., Rasmussen, S. O., Winther, O., Steig, E. J., and Axelrod, A. E.: An automated approach for annual layer counting in ice cores, Clim. Past, 8, 1881-1895, doi:10.5194/cp-8-1881-2012, 2012.

Wolff, E. W., Fischer, H., Fundel, F., Ruth, U., Twarloh, B., Littot, G. C., Mulvaney, R., Röthlisberger, R., de Angelis, M., Boutron, C. F., Hansson, M., Jonsell, U., Hutterli, M. A., Lambert, F., Kaufmann, P., Stauffer, B., Stocker, T. F., Steffensen, J. P., Bigler, M., Siggaard-Andersen, M. L., Udisti, R., Becagli, S., Castellano, E., Severi, M., Wagenbach, D., Barbante, C., Gabrielli, P., and Gaspari, V.: Southern Ocean sea-ice extent, productivity and iron flux over the past eight glacial cycles, Nature, 440, 491-496, 2006.

Yiou, F., Raisbeck, G. M., Baumgartner, S., Beer, J., Hammer, C., Johnsen, J., Jouzel, J., Kubik, P. W., Lestringuez, J., Stievenard, M., Suter, M., and Yiou, P.: Beryllium 10 in the Greenland Ice Core Project ice core at Summit, Greenland, J. Geophys. Res., 102, 26726-783794, 1997. 